\title{
Suspended micro/nano channel resonators: a review
}

\author{
A. De Pastina and L. G. Villanueva
}

This is the Accepted Manuscript version of an article accepted for publication in Journal of Micromechanics and Microengineering. IOP Publishing Ltd is not responsible for any errors or omissions in this version of the manuscript or any version derived from it. The Version of Record is available online at http://doi.org/10.1088/1361-6439/ab6df1 


\title{
Suspended micro/nano channel resonators: a review
}

\author{
Annalisa De Pastina ${ }^{1,2}$, and Luis Guillermo Villanueva ${ }^{2}$ \\ ${ }^{1}$ Centre for Research on Adaptive Nanostructures and Nanodevices (CRANN), Trinity College Dublin \\ (TCD), Ireland \\ ${ }^{2}$ Advanced NEMS Laboratory, École Polytechnique Fédérale de Lausanne (EPFL), Switzerland
}

E-mail: guillermo.villanueva@epfl.ch

\begin{abstract}
Micro- and Nano- electromechanical systems (M/NEMS) have demonstrated outstanding sensing capabilities down to the yoctogram $\left(10^{-24} \mathrm{~g}\right)$ scale in vacuum environment and cryogenic temperatures. In order to bring such extraordinary resolution levels into the study of biological processes, Suspended Microchannel Resonators (SMRs) have been developed. SMRs are hollow devices allowing for fluidic confinement inside the body of the resonator, which can thus be kept in dry environment or encapsulated in vacuum. Analyte binding and flow-through experiments can be performed, these latter enabling single-cell analysis. In this paper, we survey the progress of over the past 20 years in the field of SMRs. We review the main fabrication, transduction and packaging strategies. We also provide an insight into the working principle of the sensors and their applications to microfluidics and biology.
\end{abstract}

Keywords: M/NEMS, biosensors, microfabrication, hollow resonators

\section{Motivation}

A strong link between cell mechanics and human diseases has been demonstrated by several studies in the past two decades. Cell physical properties such as mass, stiffness or viscoelasticity represent a valid diagnostic biomarker for several pathologies like cancer, malaria and sickle cell anemia, among others (1-7). These findings, revealing the mechanical nature of many fundamental biological processes, encouraged developments in cell mechanics research (8) using a new set of dedicated Micro- and Nano- electromechanical sensors (M/NEMS) called Suspended Microchannel Resonators (SMRs), which we are going to review here (9). The main benefit of using SMRs stems from their capability of performing single cell analysis. Indeed, classical approaches such as cell culture in a petri dish collect the average response from cell populations, while SMRs can resolve individual responses from the single entities. As a result, analysis via SMRs allows to reveal sample heterogeneity and access single cell biological processes.

\section{Introduction}

M/NEMS are mechanical transducers with micro- and nano- sized moving parts. They are usually cantilever-shaped, but can also include clamped-clamped beams (CC-beams), plates, disks and bulk acoustic devices. Their fabrication relies on standard semiconductor processing techniques, enabling for efficient batch production

Advances in the field of cell mechanics as well as microand nano- technology fostered, in the past 20 years, the development of M/NEMS for life-science applications (9-11). Continuous advances in micro- and nano-fabrication techniques allow the size of mechanical devices to be comparable to the size of some biomolecules. This results in a highly sensitive mechanical response and in outstanding mass resolution, down to the detection of viruses and single molecules (12-15). Furthermore, M/NEMS can exhibit extremely high mechanical compliance, which allows for the measurement of $\mathrm{pN}$ forces generated by biological interactions, by translating them into a mechanical displacement, enhancing force responsivity $(16,17)$. 
Mechanical biosensors can operate in static or dynamic mode, depending on whether quasi-static deflection or shifts in the resonance frequency are monitored and thus related to the biological event under study. Static mode biosensors are usually cantilever shaped and typically measure surface stress or surface forces induced by the binding of biological entities such as single-base DNA, pathogens or protein biomarkers $(11,18)$. These devices have shown remarkable label-free capabilities; however, deflection is highly susceptible to nonspecific binding, temperature and flow fluctuations. Very stable flows, together with differential measurements of nonfunctionalized cantilevers help to partially circumvent spurious deflections (9). Dynamic mode biosensors are mechanical devices that vibrate close to their resonance frequency $f_{r}$, which is proportional to the square root of the ratio between effective stiffness $k$ and effective mass $m$ of the structure. Their sensing performance can be evaluated by calculating the responsivity and resolution to the target parameter (i.e. mass of the analyte landing or binding on the resonator surface). Mass responsivity $\mathfrak{R}$ is defined as the change in resonance frequency due to a change in mass, calculated as in Eq. ( 1$)(10,19)$ :

$$
\Re=\frac{\partial f_{r}}{\partial m} \approx-\frac{1}{2} \frac{f_{r}}{m}
$$

In order to achieve the highest mass responsivity, one can reduce the mass or increase the frequency of the mechanical sensor (or both).

Mass resolution $\delta m$ is the minimum detectable mass a mechanical resonator is able to perceive. $\delta m$ is given by the ratio between the frequency noise and the responsivity, as shown in Eq.( 2 ) (20):

$$
\delta m \approx \frac{\delta f}{\Re}=-2 m \frac{\delta f}{f_{r}} \approx-2 m \frac{1}{Q} \frac{\text { Noise }}{\text { Signal }}
$$

From Eq. ( 2 ) it is clear that a large quality factor $Q$ as well as a large signal-to-noise ratio are required to maximize the sensing performance. M/NEMS have demonstrated extraordinary resolutions down to the yoctogram $\left(10^{-24} \mathrm{~g}\right)$ scale (21), as a result of ideal experimental conditions such as ultra-high vacuum levels and cryogenic temperatures. Such conditions are ideal to reduce the energy dissipation due to the medium surrounding the resonator, as well as to limit thermal fluctuations, but they are not compatible with biological processes.

\subsection{Dynamic mechanical biosensors in liquid}

When tackling real time biosensing applications, like protein or DNA detection, the immersion of the resonator into fluids is almost inevitable since most biological processes naturally occur in a fluidic environment. In this scenario, fluid viscous damping causes a drop of $Q$ of several orders of magnitude and a consequential degradation of mechanical performance (22). We can identify four main strategies developed to exploit M/NEMS sensor performances for biological detection: (i) capture the analyte in fluidic phase and analyse a posteriori in vacuum environment (23); (ii) perform the measurements in a high-humidity environment (24); (iii) continuous operations in liquid, focused on enhancing the quality factor $(25,26)$; (iv) confinement of the fluidic sample inside the resonator structure (SMRs, object of this review).

In the first approach, cantilever arrays are functionalized to capture analytes directly from the fluid phase (blood serum) (23). Resonators are subsequently dried and analyzed in vacuum. Although this approach demonstrated femtomolar sensing capabilities, it does not allow for real time analysis of the biological sample.

Concerning the second strategy, certain biological species like bacteria can grow and survive in highly humid environment. In this case, even though viscous damping is larger than in vacuum, it does not reach the levels of full immersion in liquid, thus the quality factor remains acceptable. An example of this biodetection is the growth monitoring of Escherichia coli using cantilevers coated with nutritive layers (sugar) and operation in air above 93\% humidity (24).

Many other scenarios require full fluidic immersion of the M/NEMS while the measurement is running (third approach). One solution to limit the degradation of $Q$ due to the viscous damping generated by the surrounding fluid, consists in the use of acoustic modes, which are less impacted by viscous losses with respect to flexural (out-of-plane) vibrational modes. Acoustic sensors such as quartz crystal microbalance (QCM) and surface acoustic waves (SAW) devices demonstrated label-free and real-time detection of biomolecules such as DNA, protein and bacteria (26-30). To permit the use of QCM or SAW as a biosensor, analytespecific molecules are immobilized on the device surface to catch the target molecules from sample solution.

QCM consists of a quartz disk with electrodes that allow for the excitation of a shear acoustic mode, which has an inherent low viscous interaction with the surrounding fluid (31). However, in order to have devices that are not too fragile, the overall thickness is kept in the range of some millimeters, corresponding to frequencies in the tens of MHz. With such devices, the mass resolution is limited because of their own mass (thickness) (27).

SAW devices generate and detect acoustic waves using interdigital transducers (IDT) on the surface of a piezoelectric (PZE) crystal. The surface acoustic wave travels along the space between the IDTs, known as delay-line. The acoustic energy stays confined close to the surface of the PZE crystal in a depth range close to the acoustic wavelength, regardless of the thickness of the complete substrate. For this reason, the wave is potentially very sensitive towards any change on the surface, such as mass loading, viscosity and conductivity changes. The highest sensing performances of SAW devices 
have been achieved by Love mode SAW sensors, where a waveguide layer maintains the acoustic wave near the device surface $(32,33)$. SAW devices can be as thin as few hundreds of micrometers and their typical frequencies are much larger than those of QCMs. Nevertheless, the acoustic waves are not purely shear, and radiate compression waves into the liquid, which induces larger damping than in the case of shear modes, but lower than in the case of flexural (26).

As seen in Eq. ( 2 ), the minimum detectable mass that a resonator is able to measure is proportional to the mass of the device itself. In order to minimize said parameter, the optimum choice is to work with flexural devices, which can reach nanoscale dimensions and masses in the order of picograms, potentially allowing single molecule mass sensing. However, flexural devices exhibit out-of-plane vibrations, therefore their energy loss when they vibrate in a fluid environment is much larger compared to acoustic resonators. Several strategies have been implemented in order to enhance mechanical performance of flexural devices immersed in liquids, such as exciting higher vibrational modes (larger frequencies) (25), or reducing the surface of contact between liquid sample and resonator (34-36). However, confinement of the fluidic sample inside the resonator body, which is the case of SMRs, represents the best solution in terms of resolution, sensing surface and throughput (number of particles analysed per unit of time), while also enabling single cell detection.

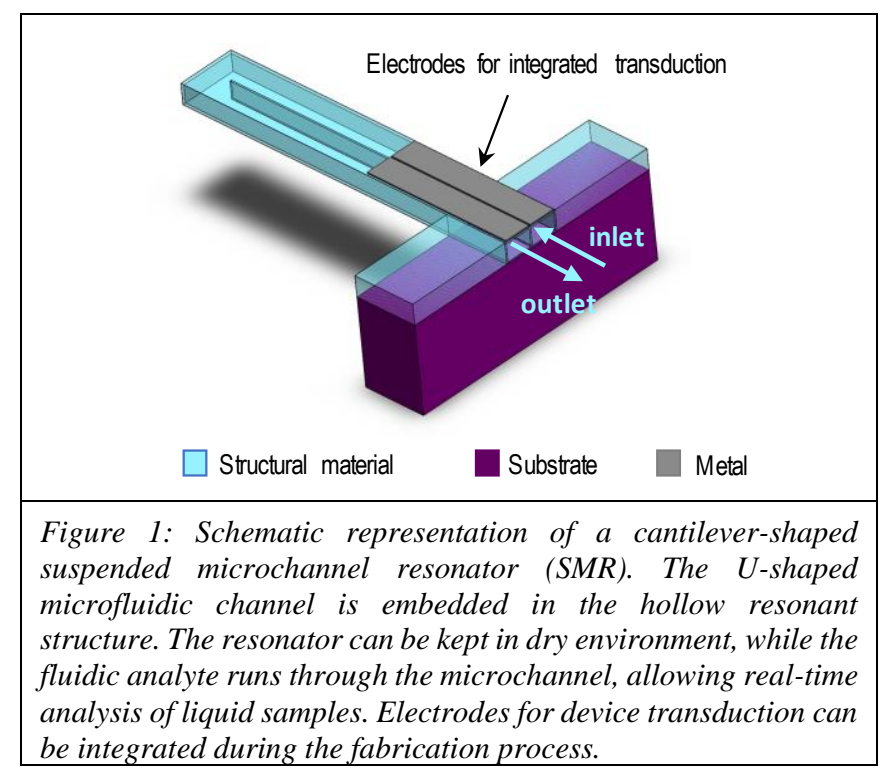

In 2003 Scott Manalis' group presented a device (37) inspired by the millimeter scale densitometer developed by Stabinger and co-workers in 1965 (38, 39). SMRs, schematically represented in Figure 1, consist of a hollow resonant structure containing embedded microfluidic channels. The fluid to be analyzed flows inside the resonator, thus viscous damping is almost completely suppressed, and mass loading is minimized. Real time analysis of fluidic samples is made possible while the whole device can be kept in dry environment, thus retaining high mechanical performance. Quality factors up to 15000 and mass sensitivities down to 1 attogram in $1 \mathrm{kHz}$ bandwidth have been demonstrated (40).

Most SMRs are cantilever-shaped resonators excited in their flexural modes. However, other hollow resonator geometries and vibrational modes have been reported in literature such as hollow clamped-clamped beams (CCbeams) and plates, or torsional and in-plane modes.

In this review, we focus on hollow resonant devices for biosensing applications. We start by providing an overview of the main fabrication strategies reported in literature, as well as the transduction approaches for the actuation and the readout of the sensors. We discuss the complex SMR chip-to-world interfacing and the packaging strategies adopted in state-ofthe art. We then review the sensing capabilities, modes of operation and the main reported applications of SMRs in microfluidics and biological field. We conclude by briefly discussing the device challenges and future perspectives.

\section{Fabrication}

SMR fabrication must meet the requirements of mechanics, microfluidics and, in case of integrated transduction, electronics. Therefore, it can be a complex, long and rather costly process.Materials and geometrical dimensions need to reach both fabrication feasibility and device functionality. Properties such as biocompatibility, chemical stability and hydrophilicity should be considered when selecting the resonator material, together with thermal budget, residual stress, etching selectivity and fabrication cost.

The main approaches developed for SMR fabrication are shown in Table 2 and can be classified in two categories: (i) fabrication processes which require the deposition of a dedicated sacrificial material for microchannel definition (Table 2, A-C); (ii) fabrication processes which do not require a sacrificial material (Table 2, D-H). Indeed, the definition of the microfluidic channel embedded in the mechanical structure represents the most challenging step of SMR fabrication.

\subsection{Process requiring sacrificial material}

The use of a dedicated sacrificial material, despite adding on an already complex fabrication process, allows the fine control of microfluidic channel geometry and dimensions.

Within this approach, it is fundamental to carefully choose a structural material that possesses excellent selectivity towards the chemical used to etch the sacrificial material in the channel. Silicon nitride/polysilicon as well as silicon oxide/silicon are good structural/sacrificial material options, considering long wet etching in $\mathrm{KOH}$ or $\mathrm{XeF}_{2}$ (41). Polysilicon $(37,42-45)$, as well as silicon oxide $(46,47)$, 
photoresist (48) and metals (49), are examples of sacrificial materials reported in literature for SMR fabrication.

The first reported SMR fabrication processes rely on the long wet etching of a sacrificial polysilicon $(37,42)$. In particular, fluidic channels are defined via deposition and patterning of the sacrificial layer deposited on top of the structural material (low stress silicon nitride, $1 \mathrm{~s}-\mathrm{SiN}_{\mathrm{x}}$ ) of the resonator. Channels are then sealed with a second silicon nitride deposition. Sacrificial polysilicon removal is achieved defining access holes at the two extremities of the fluidic channel (i.e. inlet and outlet) and immersing the wafer in wet etchant $(\mathrm{KOH})$ for several hours. This fabrication process allows to obtain fluidic channels embedded inside the flat surface of resonators or extruded from the cantilever base, as shown in Table 2.A and B, respectively. Typical channel dimensions range from few micrometer down to few hundreds of nanometers. As a drawback, several hours in aggressive chemicals (i.e. $\mathrm{KOH}$ ), can be detrimental to the wafer integrity. More recently, the same approach shown in Table 2.B was proposed with a different selection of structural/sacrificial materials (parylene/photoresist (48), silicon nitride/silicon oxide from Tetraethyl Orthosilicate (47)) that enabled shorter times for channel emptying, in the order of few minutes.

An alternative approach is the one represented in Table 2.C, where channel walls are defined by filling high-aspect ratio trenches in the sacrificial layer (45). In this case, channel emptying is achieved via the definition of discontinuous apertures that provide direct access to the channel interior along their full length. This strategy allows for fast channel emptying (within few minutes), thus preventing damages to the wafer substrate. Microfluidic channel of few micrometer size can be obtained, and their dimensions accurately finetuned. Furthermore, the etching duration is independent of channel length, enabling the controlled definition of arrays of multiple SMRs having different lengths. In addition, after channel definition, the wafer has a flat surface that enables further microfabrication processing (i.e. integration of electrodes for device transduction). However, this approach is rather costly as it requires two e-beam lithographies and several thin film depositions.

In the three cases (Table 2.A-C) the shape of the resonators is defined via photolithography and dry etching, while SMRs are finally suspended via isotropic wet or dry etching.

\subsection{Process not requiring a sacrificial material}

In order to simplify and shorten the SMR fabrication, alternative process flows have been developed, that do not require the additional deposition and etching of a sacrificial material (Table 2.D-H). In general, simpler and shorter process flows are achieved at the cost of less control in channel dimensions and cross sectional shape.
Table 2.D presents a strategy based on fusion bonding of two silicon-on-insulator (SOI) wafers, previously etched to define the microfluidic channel cavity (40, 50, 51). Photolithograpy and dry ethings are used for both SMR definiton and release. This methodology provides a simple fabrication process and a flat resonator surface. Within this category, this is the technology that provides the best control of microfluidic channel dimensions and shape. However, SOI wafers can be rather costly and several fabrication steps are still required.

Table 2.E shows a different strategy, where SMRs are fabricated defining buried cavities underneath the surface of the wafer and sealing them with a single deposition of structural material. Few examples refer to (52-54), where dashed apertures are opened via dry etching, in a low stress silicon nitride layer deposited on a silicon wafer. The underlying silicon is isotropically etched in $\mathrm{SF}_{6}$ gas, leading to the coalescence of the etched regions and to the formation of a continuous channel, about $10 \mu \mathrm{m}$ in diameter. Finally, channel walls are uniformly coated with a single low stress silicon nitride deposition, that also seals the etch apertures. Resonators are patterned and finally released in isotropic $\mathrm{SF}_{6}$ gas etching. This technique requires the engineering of dashed apertures distribution and spacing, easily achievable via simulation software or analytical modelling. In addition, it allows an easy and fast fluidic channel definition below the flat surface of the wafer, with etching times in the order of few minutes. However, it reduces the control of the dimensions and geometry of channel and resonator, compared to the previous strategies. For instance, channel dimensions are limited by the ability to control etching rate and uniformity across the wafer.

Table 2.F shows the fabrication of SMR CC-beams, via Nanoscribe ${ }^{\circledR}$ and/or Femtoprint ${ }^{\circledR}$ technology. The latter consists of femtosecond laser direct writing on a glass substrate (55). This technology is based on local material density modification via femtosecond laser exposure. As an effect, exposed regions exhibit a different etching rate in $\mathrm{HF}$ or $\mathrm{KOH}$. In addition, moving the laser focal point across the substrate thickness allows to obtain three dimensional (3D) geometries embedded in the glass wafer (i.e. hollow structures). After exposure the wafer is immersed in $\mathrm{KOH}$ solution for several hours in order to obtain released SMRs. This approach allows to dramatically simplify the SMR fabrication process and enables the fabrication of microchannel of few micrometers in diameter. However, it requires long etching in aggressive chemicals $(\mathrm{KOH})$ and does not provide optimal control of the microfluidic channel dimensions and cross-sectional shape. Another option is to use 2-photon polymerization of a negative-tone resist to directly define the channel walls, with a subsequent immersion in development solution (56). 
The fabrication technology shown in Table 2.G is based on Silicon self-assembly and enables the fabrication of hollow microtubes within a three-step process (57). This process, called silicon-on-nothing (SON) consists of the dry etching of cylindrical pores in a standard silicon substrate. The wafer is then annealed at high temperature $\left(1050{ }^{\circ} \mathrm{C}\right)$ for about 20 minutes, under a controlled Argon atmosphere. Selfassembled buried cavities, with a diameter of $1.8 \mu \mathrm{m}$, are obtained after annealing. Access holes are defined via dry etching and the wafer is later dry oxidized in a furnace to coat channel interior. Resonators are finally released in $\mathrm{SF}_{6}$ gas isotropic etching. This approach allows for the simple fabrication of hollow tube resonators, with tuneable channel wall thickness and microfluidic diameter in the range of few $\mu \mathrm{m}$. However, due to the tubular shape of the resonator arms, further microfabrication for transduction integration is rather difficult. Table 2.H shows SMRs CC-beam obtained via pulling and laser heating of commercial glass capillaries. This methodology allows to reduce the capillary diameter from few hundreds to few microns, and to increase its length by few centimeters. The obtained microchannel is flexible and can be easily folded by $180^{\circ}$. The resonator length can be defined by simply supporting the capillary at two contact points. The unpulled sections at both ends of the capillary facilitate handling and liquid delivery. However, it is difficult to achieve constant cross sectional dimensions along the pulled capillary, as well as to fine tune the resonator geometry (58).

\section{Motion Transduction}

SMR transduction needs to translate the mechanical vibration of the solid structure into a detectable electrical signal and vice-versa, for readout and actuation, respectively. Transduction approach must be selected while taking into account fabrication processes as well as packaging strategies. For instance, electrical transduction strategies have impressive degree of miniaturization, but impose high fabrication complexity and design restrictions. On the other hand, optical techniques offer great flexibility in fabrication and design, but require bulky instrumentation and complex alignment, set geometrical constraints between the optical probe and the device, and are limited at the nanoscale by light diffraction (59). Table 1 summarizes the most common actuation and detection strategies used for M/NEMS, while in Table 3 some of the several SMR publications and related transduction strategies are listed.

The most basic actuation approach for SMRs consists in using a commercial piezoceramic actuator put in contact with the chip $(42,57,60)$. In this case, a piezoelectric (PZE) block in the size range of few millimeters delivers mechanical vibration at a specific frequency, upon connection to an external voltage source. This method is extremely practical, cheap and easy to implement; however, simultaneous actuation of multiple frequencies is cumbersome, and particular care is needed in order to firmly attach or put in contact the PZE block with the chip. This strategy can also be used to reduce electrical coupling between actuation and electrical detection as done in (61), where a commercial piezoceramic actuator was used instead of integrated electrostatic actuation (available on chip), in order to avoid coupling with the piezoresistive readout. In (62), the same group superimposes piezoceramic actuation in phase with electrostatic one. The goal is to provide enough vibrational amplitude to exert nanonewton-scale centrifugal force on single particles, in order to guide them into mechanical traps within the SMR.

Table 1: Common transduction techniques for mechanical sensors at the microscale. Actuation can be achieved by applying a pressure, a force or a deformation to the device. Readout can be attained by reading an optical signal, or by sensing a generated force or deformation. Some techniques allow both actuation and readout.

\begin{tabular}{cccc}
\hline \multirow{2}{*}{ ACTUATION } & \multicolumn{1}{c}{ Pressure } & Force & Deformation \\
\cline { 2 - 4 } & $\begin{array}{c}\text { Shape Memory } \\
\text { Polymers }\end{array}$ & Magnetic & Piezoelectric \\
\cline { 2 - 4 } & & Electrostatic & Thermal \\
\hline \multirow{2}{*}{ DETECTION } & Optical & Force & Deformation \\
\cline { 2 - 4 } & Optical lever & Magnetic & Piezoelectric \\
\hline
\end{tabular}

The most widespread integrated actuation strategy found in literature for SMRs is electrostatic actuation (37, 63-65). This is achieved by defining, during SMR fabrication, two metal electrodes: one in proximity of and another one on the resonator. In general, this technique provides non-linear, but fast response with low power consumption. In addition, it can be used both in actuation and in detection (capacitive), as seen in $(50,64,66)$. The main limitations are the small achievable displacements (thus the previously mentioned superimposition with PZE block), and the lower efficiency at the nanoscale due to the scaling down of the electrodes area.

Optical-induced thermal actuation has also been reported by Craighead and coworkers, for doubly clamped low-stress silicon nitride SMRs with nano-sized channels (43). In this case, thermal expansion and contraction are induced via thermal injection in the resonator material, through an amplitude-modulated laser.

Piezoelectricity has been applied to SMR devices, not only for actuation but also for detection $(45,67)$. Piezoelectricity is a non-dissipative effect: current flowing in the PZE layer is rather low, thus avoiding heating of devices, typical of optical or piezoresistive techniques $(68,69)$. It provides a fast and linear response and enables both actuation and detection (70). Efficient piezoelectric actuation of SMR arrays has been recently reported in (45). An aluminium nitride PZE layer sandwiched between two Pt electrodes was integrated near the clamp of SMR arrays, enabling individual resonator transduction, both in actuation and readout. 
Table 2: Overview of the main microfabrication strategies for SMRs. The different approaches can be divided in the ones requiring a dedicated sacrificial material $(A-C)$ and the ones not requiring the deposition of a sacrificial material $(D-H)$. The additional process steps necessary for the integration of electrical transduction are not considered in this table. In the center, the schematic process flow is represented in cross section, while the right column shows real images of fabricated devices.

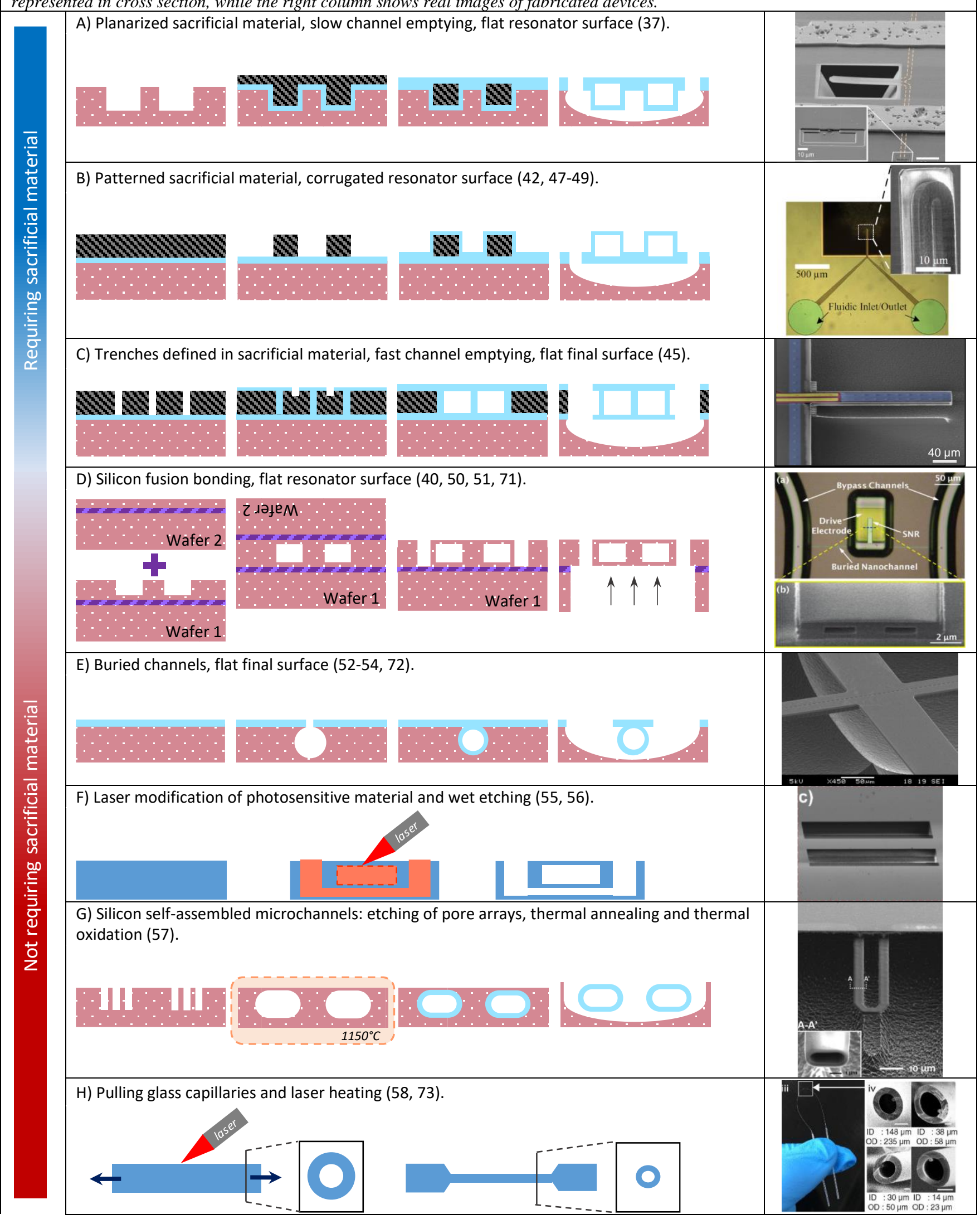


SMR readout has been largely performed via optical lever and interferometry, as can be seen in Table 3. A close feedback loop configuration involving $n$ phase locked loops (PLLs) was recently implemented for the optical readout of $n$ SMRs: devices were arranged in an array configuration and actuated by a piezoceramic actuator, driven by the sum of the $n$ signals demodulated by the PLLs (60).

SMR integrated electrical readout has been demonstrated, not only via piezoelectricity and capacitive technology, as already mentioned, but also via piezoresistive detection (61, 74), as shown in Table 3. Piezoresistive sensors can be fabricated close to the resonator anchor, via ion implantation into single crystal silicon (61). The deflection of the cantilever induces a change in resistance in the piezoresistor that can be measured with a Wheatstone bridge. Piezoresistive readout is easily implemented in large arrays and it is linear for small displacements. However, this is a dissipative phenomenon (thermal dissipation via Joule effect) and the thermal noise associated to thin piezoresistive layers can limit detection efficiency.

\section{Packaging and interfacing}

Packaging in vacuum and device-to-world interfacing are fundamental steps to connect microfabricated devices to external equipment and make them operational in a comprehensive experimental setup. Microfluidic and electrical interconnections need to be planned during the design stage, in order to take into account size-limitations, material compatibilities and geometrical configurations (75). For instance, microfluidics does not scale together with microelectronic miniaturization, which makes fluidic delivery and control a challenge at the nano and microscale. In addition, packaging cannot be standardized as it depends on the specific application of the sensor to characterize (76). Hence, custom experimental platforms need to be engineered to support efficient operation of devices.

In order to operate SMR sensors, key requirements are: (i) provide fluidic connection, in order to efficiently interface millimeter-scale commercial tubing to the micrometer-sized embedded channels. (ii) Provide electrical connection (in case of integrated transduction), for example via wire bonding to a printed circuit board (PCB). (iii) Stabilize the temperature of the sensors, in order to avoid crosstalk due to temperature shifts. (iv) Encapsulate the devices in vacuum, in order to maximize SMR resolution, according to Eq. (2)

The methods reported in literature for SMR packaging are based on two main approaches: (i) Wafer-level packaging (Figure 2.A); (ii) Chip-level plug-and-play configuration (Figure 2.B).

Both strategies show optimal control and reliability, and are schematically represented in cross section and $3 \mathrm{D}$ rendering in Figure 2 (left and right column, respectively).
Other simpler approaches can also be found in literature. For instance, in (43) NanoPort Assemblies (IDEX-HS) are glued directly to the chip for fluidic delivery and to serve as fluid reservoir. NanoPorts are then closed with commercial fittings to ensure fluidic confinement, allowing the assembled chip to be placed in a vacuum chamber for in-vacuum operation.

\subsection{Wafer-level vacuum packaging}

Wafer-level vacuum packaging entails the vacuum encapsulation of the whole SMR wafer that can be subsequently diced in chips for individual interfacing to fluidic and electronic equipment $(40,60,77,78)$. It constitutes an elegant and permanent solution. However, additional process steps are required, further complicating the process flow and increasing the fabrication costs.

Wafer-level packaging can be achieved via SMR wafer bonding to a glass substrate. In (40), the glass wafer also includes patterned bypass channels for fluid delivery, as well as electrical connections for electrostatic actuation. Devices are sealed at pressures below $10^{-3} \mathrm{mbar}$, and an on-chip getter (SAES, Italy) ensures stable vacuum levels over extended time periods.

\subsection{Chip-level plug-and-play configuration}

Chip-level plug-and-play configuration allows to reversibly encapsulate the chip in a modular platform, where fluidic connections and vacuum sealing are provided, together with temperature control (79-81). This is a lower cost and fully reversible approach, but requires more manual handling and plugging by the operator.

In (81), an o-ring based modular interface is described (Figure 2.B). The SMR chip is sandwiched between a micromachined fluidic connector and a metal plate. The fluidic connector contains bypass channels for fast exchange of fluidic samples. In addition, a central cavity is used to (i) provide visual access to SMRs and fluidic inlets/outlets for alignment; (ii) create an on-chip vacuum chamber, via connection to a vacuum pump and sealing with a glass lid. The metal plate is in contact with a Peltier cell and a thermistor to maintain stable temperature during experiments. Electrical connections are provided via wire bonding of the SMR chip to a PCB. A similar configuration is proposed in (79), where fluid delivery and vacuum encapsulation are totally decoupled: fluid samples are delivered from the backside of the chip, while an on-chip vacuum chamber is built in the front. Another example, but not including vacuum encapsulation, is given in (51), where a customized plug-andplay platform with electrical spring probes and o-ring based fluidic sealing is presented. 


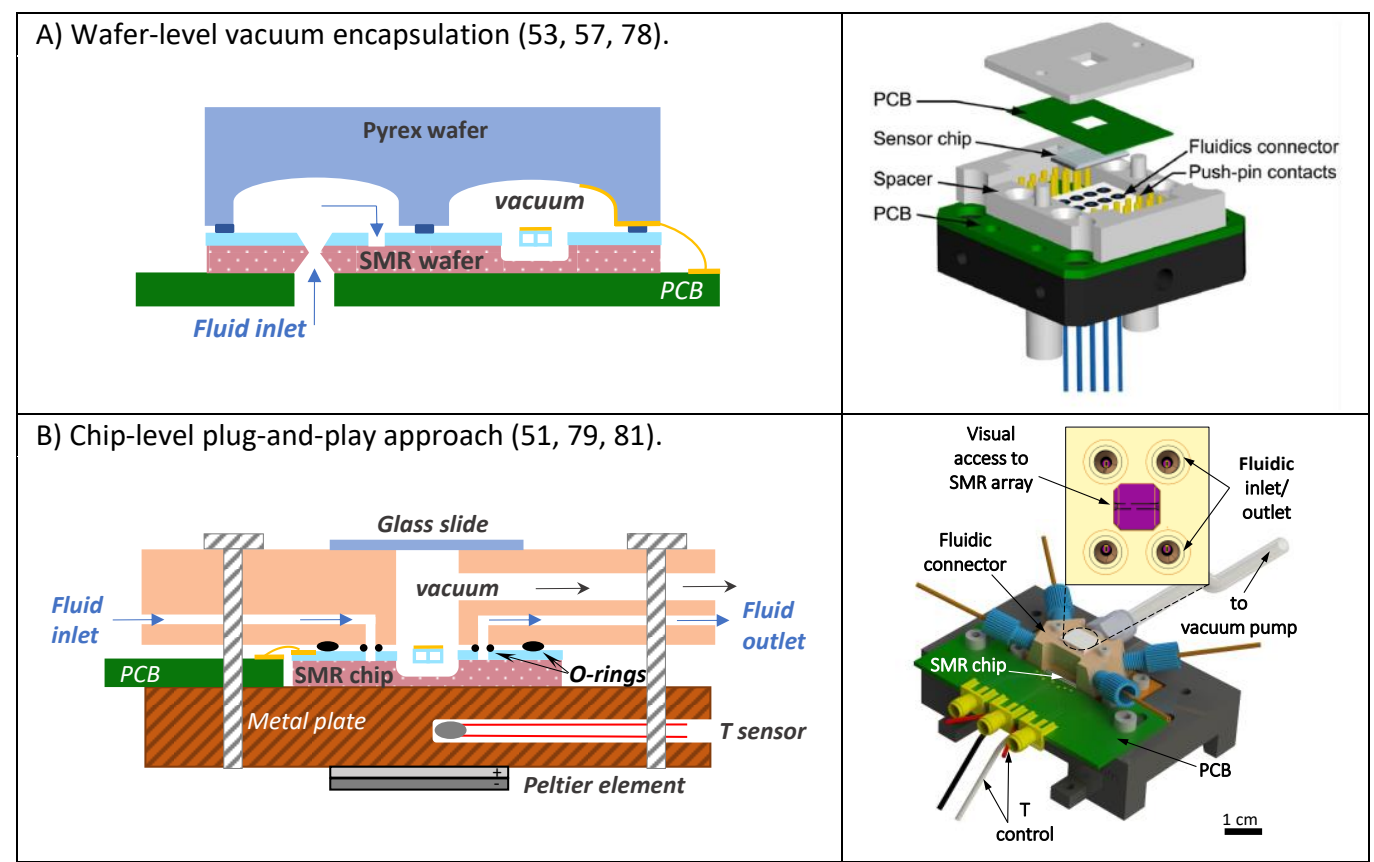

Figure 2: Simplified schematic (left) and 3D rendering (right) of the two main SMR packaging and interfacing approaches. A) Wafer-level vacuum encapsulation, achieved via pyrex wafer bonding to the SMR wafer, which can be later cleaved into chips and interfaced to fluidics and electronic connections. B) Chip-level plug-and-play approach, totally reversible and exchangeable within different chips, but requiring manual operation for alignment and assembly.

\section{Sensing capabilities}

SMRs have the capability to sense any magnitude directly affecting their mechanical response. This includes sensing of mass, mass density, viscosity, stiffness, temperature and heat, among others.

According to the resonator geometry, SMRs can be operated both in static and dynamic mode. Flexural resonators (i.e. cantilevers) are the most exploited geometry in literature, as can be seen in Table 3, because of their excellent resolution and because they enable both static and dynamic operation.

\subsection{Static mode operation}

The standard static operation of classic cantilevers consists in detecting the quasi-static deflection induced by a difference of surface stress between the two faces of the resonator. This is in general the result of biomolecules binding on the functionalized surface of the cantilever. When considering SMRs, this strategy is difficult to be applied because the functionalization of the embedded microchannel would result in a uniformly distributed binding of receptors on all channel walls. In order to have a proper response, the asymmetry needed in the SMR structure (microfluidic channel position with respect to the cantilever neutral axis) should be so large that it becomes unrealistic (82).

Static deflection of bimaterial SMR cantilevers has been applied in the field of photothermal spectroscopy (44). In this application the SMR can be considered as a thermal sensor, and its deflection amplitude is studied as a function of the wavelength of the absorbed light. The SMR has a bimaterial composition that results in thermal expansion mismatch between the layers, thus enhancing temperature responsivity. This approach does not require chemical functionalization, therefore it overcomes difficulties related to chemical preparation and binding specificity.

Force spectroscopy is another field example of SMR operated in static mode (49). Hollow cantilevers with an open tip measured adhesion forces of single cells immobilized on a substrate, in liquid environment. In this case, the open microfluidic channel is not filled with a fluid, but it serves to apply a negative pressure on single cells to partially overcome and study their adhesion forces on the substrate. Despite sub$\mathrm{nN}$ resolution, this technique is rather slow (in the order of few cells per minute), since careful alignment of the SMR to each cell is required.

\subsection{Dynamic mode operation}

The vast majority of SMR publications focuses on sensors operating in dynamic mode (see Table 3). The main reason is that this approach enables several strategies to maximize device resolution, such as signal averaging, working at the onset of mechanical nonlinearities and applying frequency noise cancellation techniques $(20,69,83)$.

In general, an analyte flowing through or binding on the resonator induces a relative frequency shift which is proportional to the analyte mass and stiffness (69). This has been exploited via two modalities of operation: (i) affinity- 
based capture, based on the immobilization by molecular recognition of the analyte on the functionalized surface of the microchannels (Figure 3.A); (ii) Flow-through detection, which consists in monitoring the SMR frequency response in real time, as single particles run through the resonator (Figure 3.B).

\subsubsection{Affinity-based capture}

This approach allows to detect target biomolecules binding inside the SMR, upon functionalization of the microfluidic channel walls. It is therefore possible to measure the concentration of these molecules in solution. The exact (buoyant) mass of accumulated molecules can be quantified by measuring the resonance frequency before and after injection of the target analyte $(40,78)$. In fact, molecular capture causes an increase of the resonator mass, which induces a frequency shift $\Delta f_{r}$ towards lower frequencies, as shown in Figure 3.A, and directly proportional to the accumulated mass. Importantly, since measurements are made in liquid, the mass that generates changes in the resonant frequency is the buoyant mass, i.e. the mass of the analyte minus the mass of the displaced fluid (84).

\subsubsection{Flow-through detection}

Flow-through detection consists in tracking the SMR resonance frequency while an analyte runs through the embedded channel. A particle travelling through the SMR induces a transient frequency shift, directly related to the particle mass and stiffness, and function of the cell position along the U-shaped channel (69). When the analyte flows through the clamp of the resonator (position 1 and 3 in Figure 3.B), a shift towards higher frequencies is expected, due to the particle stiffness contribution to the SMR resonance frequency. Conversely, a relative frequency shift towards lower values is measured when the analyte travels close to the SMR tip, where its buoyant mass contribution is maximum.

A slight variation of this strategy consists in trapping the analyte at the tip of the resonator via centrifugal force, and subsequently release it by increasing the flow rate $(71,85)$. This nice tactic has a double effect: it enables longer averaging times, enhancing the resolution. It also allows to suppress the measurement error due to uncertainty in the lateral position of particles travelling through the U-turn at the tip of the cantilever (40). Another method to circumvent this latter issue is to excite the SMR in its second flexural mode of vibration and make the U-turn around the nodal point of the mode, rendering it nearly insensitive to the lateral position of the particle in the channel (85).

Flow-through detection approach has the great advantage to allow real-time monitoring of single particles. Furthermore, measurements do not require chemical treatment of the channel surface or the use of expensive reagents. Flowthrough detection applications have achieved mass resolution down to the attogram precision, for the case of nano-sized fluidic channels (86). However, the main limitation of SMRs operated in such configuration is throughput, as will be discussed in Section 8. Challenges.

Stiffness detection is considerably more challenging, as its effect on the resonance frequency is orders of magnitude lower than the mass contribution $(69,87)$. However, single cell stiffness sensing has recently been demonstrated, by combining SMRs with acoustic technology, as described in the next section (88).

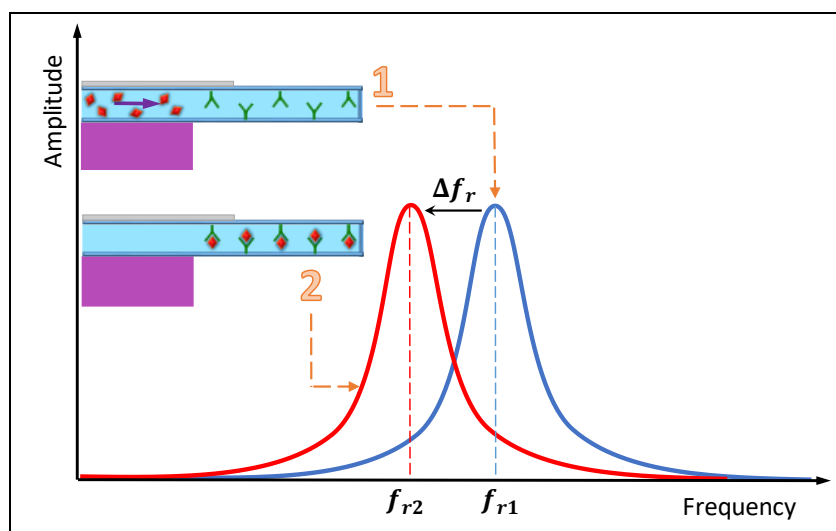

A)

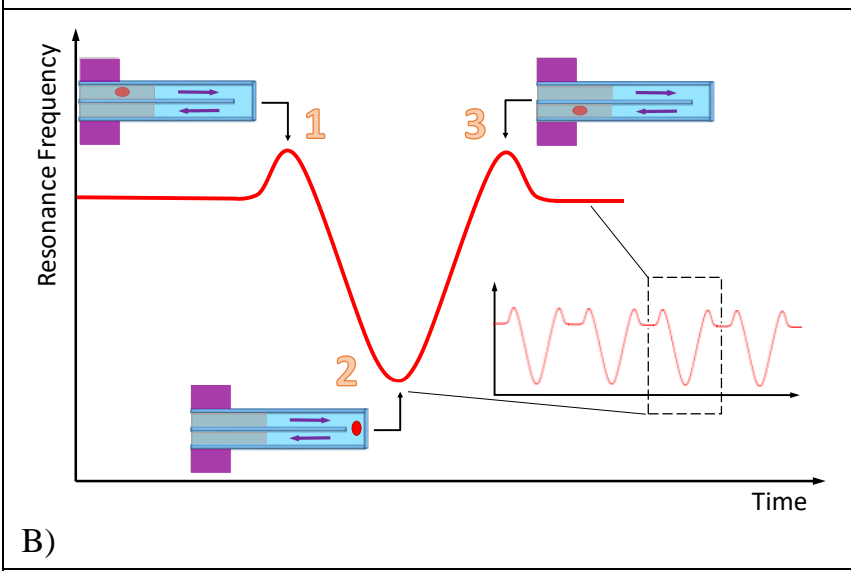

Figure 3: SMR dynamic modes of operation. A) In affinity-based capture operation, molecules are immobilized onto the channel walls, via biomolecular recognition. Particle accumulation induces a frequency shift $\Delta f_{r}$, directly proportional to the accumulated mass. B) Flow-through detection allows the realtime analysis of single particles. Transient resonant frequency shift can be detected, as a function of particle mass, stiffness and position along the microchannel.

\section{Applications}

SMRs with micro- and nano-scale channels have demonstrated great sensing capabilities down to the attogram scale and have been used in a plethora of applications such as characterization of the rheological properties of fluidic samples, as well as single cell measurements of mass, density and growth. SMRs have also been combined with other 
technologies, such as electrophoresis, acoustic scattering and infrared (IR) spectroscopy, further expanding their field of application to single particle surface charge, stiffness and IR absorption.

Table 3 provides a detailed summary of SMR main applications. Per each publication considered, fabrication, transduction and packaging strategies, limit of detection, geometrical and mechanical parameters are listed. A schematic classification of SMR applications is shown in Figure 4.

\subsection{Characterization of fluids}

The concept of hollow resonator dates back to 1965, when Stabinger and co-workers employed a hollow glass tube to measure the density of milliliter liquid samples $(89,90)$. The miniaturization of devices enabled the application of this concept to the characterization of the rheological and thermal properties of microfluidic samples, down to few femtoliters.

In (50), a vacuum-encapsulated silicon tube is used as fluid density sensor, providing a measurement of water density at different temperatures and reaching density resolution down to $4 \mu \mathrm{g} / \mathrm{ml}$. Similar applications were reported in further publications, where miniaturization and design optimization allowed to reach density resolution of $1 \mu \mathrm{g} / \mathrm{ml}(45,55,57,58$, 79).

Combining resonance frequency and quality factor measurements, fluidic viscosity was also resolved down to 25 $\mu \mathrm{Pa} \cdot \mathrm{s}(79,91)$. However, this technique is only valid in a narrow viscosity range, due to the non-monotonic behaviour of quality factor as a function of fluid viscosity, a complex phenomenon peculiar of SMR devices and largely studied in literature (92).

Bimaterial bridge resonators with embedded microfluidic channels have been used for thermal fluidic analysis (46). The resonator surface is locally heated via irradiated laser power of a laser Doppler vibrometer, also used to measure the frequency response of the device. The different thermal expansion coefficients of silicon nitride and silicon dioxide, structural materials of the resonator, induce an internal tensile stress. This, in turn, is used to detect the local temperature in the fluidic channel, based on resonant frequency variations. The authors measured a local heat responsivity at the center of the bridge of $8.6 \mathrm{ppm} / \mu \mathrm{W}$ and a temperature responsivity of $140 \mathrm{ppm} / \mathrm{K}$, demonstrating potential application to single cell calorimetry.

\subsection{Characterization of floating particles and molecules}

Functionalizing the inner surface of microchannel walls, SMRs are capable of immobilizing molecules flowing in solution. Affinity-based detection enables measurement of particle concentration in liquid medium $(40,78)$. A relevant example is given in (93), where the authors developed a labelfree surface binding assay that allowed for picomolar detection of target proteins in undiluted serum, reaching a limit of detection of $10 \mathrm{ng} / \mathrm{ml}$.

When operating SMRs in flow-through configuration, mass detection of single floating particles is the most exploited application, as can be seen in Table 3. This application does not require surface functionalization, since it is usually performed in flow-through configuration. Device and measurement setup optimization allowed to reach mass resolutions down to few ag in $1 \mathrm{kHz}$ bandwidth, resolving nanoparticles down to $10 \mathrm{~nm}$ in diameter, with a throughput of more than 18000 particles per hour (86). SMR is the only technology that allows for this outstanding combination of mass resolution and throughput. In addition, single particle mass measurements can be exploited to obtain other fundamental parameters such as cell mass density, cell growth, mass accumulation rate and response to drugs.

The mass density of single cells has been measured via SMRs with a precision down to $1 \mathrm{mg} / \mathrm{ml}$. The general measurement approach consists of detecting the buoyant mass of flowing cells in different fluids of known densities. In (94), a cell travels through the whole SMR length, and pauses in an exit bypass channel containing fluid of a higher density; subsequently, the flow direction is reversed so the cell can travel a second time through the SMR in the opposite direction, to be measured in the second fluid. This method requires absolute control of pressure and flow within the SMR device. In addition, the throughput is limited to up to 15 seconds per cell, due to two requirements: each cell is forced to flow twice through the same resonator, and the two fluids should be sufficiently mixed by diffusion before reversing the flow. An alternative configuration is presented in (62), where mechanical traps are integrated inside the SMR to physically trap a single cell. This approach allows to continuously monitor cell buoyant mass and density while the surrounding fluids are exchanged, also enabling larger integration times. Although mechanical trapping enables better resolution and additional information with respect to the previous strategy, it also adds microfabrication complexity. Furthermore, pressure fluctuations during fluidic exchange can cause the cell to escape the trap; also, cell expulsion from the trap requires large differential pressures and can it be difficult due to cell adhesion to the trap walls. Another strategy to measure single cell density is presented in (95), where two SMRs connected in series are exploited. The two devices are filled with fluids of different known densities and connected by a long serpentine channel to ensure mixing. High-throughput measurements of cancer cell mass and density is demonstrated. Clearly, accurate measurement of both buoyant mass and density of a single particle allows to easily estimate its volume, thus providing a multiparametric characterization at a single cell level.

Another quantity that can be derived from measurements based on mass detection is mass accumulation rate (MAR), 
defined as the increment in mass per unit of time. MAR directly relates to cell growth. The simplest strategy to measure cell growth consists in repeatedly flowing a cell back and forth through the same resonator (94). However, in order to achieve larger throughputs and avoid the same cell to travel multiple times through a single device, the best solution is implementing SMR arrays connected in series. In (60), an array of 10-12 SMRs allows to measure the buoyant mass of the same cell as it flows through multiple resonators. Inserting long serpentine delay channels between each resonator provides the cell time to grow between consecutive measurements. In addition, multiple cells can be loaded in the array, as long as the dilution is adequate to ensure one single analyte per SMR. This approach has achieved MAR down to $0.02 \mathrm{pg} / \mathrm{h}$ for bacteria, and a throughput of $\sim 60$ cells per hour. Furthermore, single-cell MAR measured over many hours allows to accurately determine the response and resistance to drugs (96). In (97), a MAR assay reveals response to drugs in primary human multiple myeloma cells, demonstrating its potential to be used to predict therapeutic response on clinical samples. In (98), measurements of mass and growth rate via SMRs are linked to genomic profiling at single cell level, providing unprecedented knowledge in terms of biophysical signature of single biological entities. This is achieved via the development of a SMR serial platform with a downstream collection mechanism: the last analysed cell exiting the SMR array is captured into a polymerase-chain reaction (PCR) tube for RNA sequencing.

SMR devices combined with electrophoresis achieved measurement of surface charge of single particles (99). A sinusoidal electric field applied longitudinally to the SMR causes the particle flowing through the channel to oscillate at the same frequency of the applied field. Spectral analysis of the resulting resonance frequency signal over time allows to extract the particle electrophoretic mobility. This latter parameter, combined with the buoyant mass information, can be used to compute size, absolute mass and surface charge of discrete microparticles, providing the means of quantitatively differentiating complex particle mixtures.
Singe cell stiffness detection with high temporal resolution ( $<1 \mathrm{~min}$ ) has recently been demonstrated, via the combination of SMRs with acoustic technology. In (88), the authors use the vibration of a SMR in its second flexural mode as an acoustic energy source. A particle travelling through the SMR interacts with the generated acoustic field. The particle interaction with the surrounding fluid causes acoustic scattering, which shifts the resonance frequency of the device. The relative frequency shift is measured when the particle is at the node, where its mass has negligible effect on the resonance frequency (69). Hence, the authors demonstrate via experiments and FEM simulations that the frequency deviation at node is related to the cell mechanical properties and is generated by the acoustic scattering from the cell's surface.

The static mode operation of SMRs has showed promising results in the field of single molecule spectroscopy. Photothermal cantilever deflection spectroscopy (PCDS) combines the high thermal responsivity of a bimaterial SMR with highly-selective mid-infrared (IR) spectroscopy (44). This application consists in measuring the static thermomechanical response of a bimaterial SMR subjected to periodic heating by IR radiation of varying incident powers. Bimaterial SMRs achieved a minimum power measurement of $60 \mu \mathrm{W}$ and an energy resolution of $\sim 240 \mathrm{~nJ}$, which are promising results towards biomolecule sensing and analysis of bioreactions in confined volumes.

Another static mode application of hollow resonators is single cell force spectroscopy, demonstrated in (49). SU-8 flexible SMRs with an opening at the tip measure adhesion forces of single cells in the sub-nN range. The measurement is performed in liquid environment and cells are immobilized on a substrate. The cantilever tip is put in contact with the cell while the microfluidic channel serves to apply a negative pressure for aspiration. The deflection of the cantilever is monitored via optical readout and related to cell elasticity and adhesion forces.

\begin{tabular}{|c|c|c|c|}
\hline STATICMODE OPERATION & \multicolumn{2}{|c|}{$\begin{array}{l}\text { - Photothermal spectroscopy } \\
\text { - Force spectroscopy }\end{array}$} & \\
\hline \multirow{3}{*}{ DYNAMICMODE OPERATION } & \multirow[t]{3}{*}{ Fluid samples } & $\begin{array}{l}\text { - Fluidic density } \\
\text { - Fluidic viscosity } \\
\text { - Local heat in fluids }\end{array}$ & \\
\hline & & \multirow[t]{2}{*}{ Affinity-based } & - Particles and molecules concentration in solution \\
\hline & & & $\begin{array}{l}\text { - Mass } \\
\text { - Mass density } \\
\text { - MAR } \\
\circ \text { Cell growth } \\
\circ \text { Response to drugs } \\
\circ \text { Genomic profiling (SMRs combined with PCR) } \\
\text { - Surface charge (SMRs combined with electrophoresis) } \\
\text { - Stiffness }\end{array}$ \\
\hline
\end{tabular}




\section{Challenges}

M/NEMS sensors have the unique ability to sense diverse parameters of biological systems. Their miniaturization to the micro- and nanoscale enables the mechanical properties of living cells to be directly correlated with their biological activities. However, the market of biological detection is mainly occupied by electrical and optical sensors, which have been studied for over 30 years and constitute a robust and well-established technology. The main reason is that M/NEMS technology suffers from a number of disadvantages, including reproducibility and reliability in signal response thus making its application to the medical field still limited. Exhaustive discussions about the comparative advantages and the challenges of M/NEMS for biological detection can be found in excellent reviews available in the literature $(9,100)$.

In particular, SMRs constitute nowadays the best trade-off between resolution and throughput, and have the unique capability to perform multi-physical characterization at the single cell level. Nevertheless, these sensors can be extremely complex to fabricate and to operate.

As seen in section 3, several different strategies have been developed in order to reduce and simplify SMR fabrication process. Simpler fabrication strategies (e.g. glass fiber pulling or laser modification of quartz) dramatically reduce fabrication cost, time and complexity. However, these techniques usually do not provide for transduction and packaging, which therefore need to be implemented at a later stage per each device. Furthermore, some of these processes require the use of higher loss materials and result in loss of dimension control, thus negatively affecting sensing performance.

Concerning SMR operation, the main limitation of these sensors is measurement throughput. In the case of flowthrough detection, throughput is limited by the minimum residence time of the particle inside the channel, in order to enable sufficient averaging to obtain a detectable signal above the noise floor (101). Throughput can be improved via sample preconcentration or measurement parallelization, as stated in (101). For instance, a valid approach could be the implementation of large arrays of SMRs connected in parallel. However, this would not only increase the complexity of the microfluidic network, but also yield higher chances for channel breaking or clogging.

Another option to improve throughput is to reduce the noise floor of the measurements. As an example, in (86), improvements in the detection system enabled precise mass quantification of nanoparticles with a throughput of more than 18000 particles per hour. This was achieved reducing the size of the microfluidic channels that, at the same time, results into a larger fluidic resistance. Therefore, despite enhanced resolution, nano-sized channels require extremely large pressures to be operated, once again increasing experimental complexity and increasing the chances of structural damage to the devices or to the cells within the experiment.

In case of affinity-based operation, throughput is limited by the kinetics of molecule diffusion and binding, which determine both the flow rate and the channel dimensions. Surface capture can be improved by maximizing the microchannel cross section, which would also allow to increase throughput. However, bigger channels would result in heavier devices thus lowering mass resolution. A good compromise is to fabricate wider channels in order to provide surface area for binding, while minimizing the thickness of the device in order to reduce the total mass.

As a general remark for all modes of operation, a trade-off between throughput and resolution must be found when designing the resonators.

Definitely, the exceptional characteristic of SMRs of enabling the determination of different parameters within a single experiment comes at the cost of great experimental complexity. For instance, in the case of mass density measurements, the buoyant mass of single cells needs to be measured in two different fluids. This requires the development of protocols for cell trapping, quick fluidic exchange, or reversing the flow direction, as explained in section 7. Alternatively, a simpler but not integrated solution could be the coupling of an SMR with a flow cytometer, in order to estimate the size of each cell. Combining the size information with the buoyant mass provides a straightforward evaluation of the mass density.

SMR sensors possess extraordinary sensing capabilities that have the power to offer unprecedented insight in biological molecules and their biophysical functions. However, technological and experimental complexity constitute a limitation to their widespread application on the biological market. Further considerations about SMR practical limitations can be found in an excellent dedicated review by Arlett and Roukes (101).

\section{Conclusion and Outlook}

In this paper we have provided a succinct revision of the current state of the art on suspended microchannel resonators. We offer different ways to classify them: based on fabrication, packaging and application. This review is meant to help other researchers to quickly catch up with the latest advances on the topic and to realize of the potential of these devices for fundamental research but also as laboratory tools, for example for diagnostics.

We are currently in a crucial point where the fabrication technology is mature and integration is more stable, so naturally applications are going to multiply. Several start-up companies have been created in the past few years and many more are yet to come. We believe that the most interesting directions where the field of SMRs can really make a 
difference are in the study of physical attributes (physical phenotyping) of single-cells with high throughput.

\section{Acknowledgements}

The authors acknowledge financial support from the Swiss National Science Foundation (PP00P2-144695 and PP00P2170590) and the European Commission (PCIG14-GA-2013631801). 


\begin{tabular}{|c|c|c|c|c|c|c|c|c|c|c|c|c|c|}
\hline \multirow[t]{2}{*}{$\begin{array}{l}\text { Group } \\
\text { and } \\
\text { year }\end{array}$} & \multirow[t]{2}{*}{ Geometry } & \multirow[t]{2}{*}{ Material } & \multirow[t]{2}{*}{$\begin{array}{c}\text { Fabrication } \\
\text { type* }\end{array}$} & \multirow[t]{2}{*}{$\begin{array}{l}\text { Sample } \\
\text { Volume }\end{array}$} & \multirow[t]{2}{*}{$\begin{array}{c}\text { Solid/Li } \\
\text { quid } \\
\text { volume }\end{array}$} & \multirow[t]{2}{*}{$\begin{array}{l}\text { Actuation } \\
\text { Method }\end{array}$} & \multirow[t]{2}{*}{$\begin{array}{l}\text { Readout } \\
\text { method }\end{array}$} & \multirow[t]{2}{*}{$\begin{array}{l}\text { Resonance } \\
\text { Frequency** }\end{array}$} & \multirow[t]{2}{*}{$\begin{array}{l}\text { Quality } \\
\text { Factor*** }\end{array}$} & \multicolumn{2}{|c|}{ Limit of Detection } & \multirow[t]{2}{*}{$\begin{array}{l}\text { Packaging } \\
\text { strategy }\end{array}$} & \multirow[t]{2}{*}{ Target/Application } \\
\hline & & & & & & & & & & Responsivity & Resolution & & \\
\hline $\begin{array}{l}\text { Stabinger } \\
1965(39, \\
90)\end{array}$ & hollow tube & Glass & $\begin{array}{c}\text { Glass } \\
\text { technology }\end{array}$ & $1 \mathrm{ml}$ & N.A. & Magnetic & $\begin{array}{l}\text { Digital } \\
\text { counter }\end{array}$ & $\begin{array}{l}\sim 10 \mathrm{kHz} \\
\text { (torsional) }\end{array}$ & N.A. & Accuracy of $10^{-6}$ & N.A. & N.A. & Fluid density \\
\hline $\begin{array}{l}\text { Stemme } \\
2000(50)\end{array}$ & tube loops & Silicon & D & $0.035 \mathrm{ml}$ & 0.06 & Electrostatic & Capacitive & $\begin{array}{l}\sim 10 \mathrm{kHz} \\
\text { (torsional) }\end{array}$ & 3400 & $\begin{array}{l}200 \mathrm{ppm} /\left(\mathrm{kg} \mathrm{m}^{-3}\right) \\
29 \mathrm{ppm} /{ }^{\circ} \mathrm{C} \text { ( in 20- } \\
\left.100^{\circ} \mathrm{C} \text { range }\right)\end{array}$ & $4 \mu \mathrm{g} / \mathrm{ml}$ & A & Fluid density and temperature \\
\hline $\begin{array}{l}\text { Manalis } \\
\text { 2003 (37, } \\
80)\end{array}$ & cantilever & $\begin{array}{l}\text { low stress } \\
\text { Silicon } \\
\text { Nitride }\end{array}$ & A & $27 \mathrm{pl}$ & $\sim 1$ & Electrostatic & Optical & $\sim 40 \mathrm{kHz}$ & $\sim 90$ (in air) & $2.6 \mathrm{ppm} / \mathrm{pg}$ & $\begin{array}{c}1 \mathrm{ng} / \mathrm{cm}^{2} \text { in } 4 \mathrm{mHz}- \\
4 \mathrm{~Hz} \mathrm{BW}\end{array}$ & B (no vacuum) & Affinity-based protein detection \\
\hline $\begin{array}{l}\text { Manalis } \\
2007(40)\end{array}$ & cantilever & Silicon & D & $9.6 \mathrm{pl}$ & $\sim 7$ & Electrostatic & Optical & $\sim 220 \mathrm{kHz}$ & 15000 & $\sim 15 \mathrm{ppm} / \mathrm{pg}$ & $\begin{array}{c}0.01 \mathrm{ng} / \mathrm{cm}^{2} \\
300 \text { ag in } 1 \mathrm{~Hz} \mathrm{BW}\end{array}$ & A & $\begin{array}{l}\text { Affinity-based detection of single } \\
\text { molecules. } \\
\text { Flow-through detection of } \\
\text { nanoparticles and bacteria. }\end{array}$ \\
\hline $\begin{array}{l}\text { Elwenspo } \\
\text { ek 2008 } \\
(102)\end{array}$ & CC-beam & $\begin{array}{c}\text { low stress } \\
\text { Silicon } \\
\text { Nitride }\end{array}$ & E & $\sim 1 \mathrm{nl}$ & $\sim 0.04$ & Thermal & Resistive & N.A. & N.A. & $0.2 \mathrm{uV} /\left(\mathrm{nl} \mathrm{min}^{-1}\right)$ & N.A. & N.A. & Thermal flow sensor. \\
\hline $\begin{array}{l}\text { Manalis } \\
2008 \\
(103)\end{array}$ & cantilever & Silicon & D & $10 \mathrm{pl}$ & $\sim 7$ & Electrostatic & Optical & $\sim 200 \mathrm{kHz}$ & 15000 & $0.1 \mathrm{ug} /(\mathrm{ml} \mathrm{mHz})$ & $\sim 3 \mathrm{ug} / \mathrm{ml}$ & A & $\begin{array}{l}\text { High-performance liquid } \\
\text { chromatography (HPC). Flow- } \\
\text { through operation. }\end{array}$ \\
\hline $\begin{array}{l}\text { Manalis } \\
2009 \text { (99) }\end{array}$ & cantilever & $\begin{array}{l}\text { Silicon- } \\
\text { Silicon } \\
\text { dioxide }\end{array}$ & D & $10 \mathrm{pl}$ & $\sim 7$ & $\begin{array}{l}\text { Commercial } \\
\text { Piezoactuator }\end{array}$ & Optical & $\sim 200 \mathrm{kHz}$ & 15000 & N.A. & $\begin{array}{c}\text { particles diameter < } \\
\text { 3um }\end{array}$ & A & $\begin{array}{l}\text { Mass and surface charge of } \\
\text { microparticles. Flow-through } \\
\text { operation. }\end{array}$ \\
\hline $\begin{array}{l}\text { Manalis } \\
2010 \text { (93) }\end{array}$ & cantilever & $\begin{array}{c}\text { Silicon- } \\
\text { Silicon } \\
\text { dioxide }\end{array}$ & D & $10 \mathrm{pl}$ & $\sim 7$ & Electrostatic & Optical & $\sim 200 \mathrm{kHz}$ & 15000 & $46 \mathrm{ng} / \mathrm{cm}^{2} / \mathrm{Hz}$ & $10 \mathrm{ng} / \mathrm{ml}$ & A & $\begin{array}{l}\text { Affinity-based picomolar detection of } \\
\text { proteins in undiluted serum. }\end{array}$ \\
\hline $\begin{array}{c}\text { Manalis } \\
2010(84, \\
104)\end{array}$ & cantilever & Silicon & D & $\begin{array}{c}10 \text { to } 50 \\
\text { pl }\end{array}$ & 1 to 7 & Electrostatic & Optical & $\sim 10^{2} \mathrm{kHz}$ & $\sim 10000$ & N.A. & $3 \mathrm{fg}$ in $1 \mathrm{~Hz} \mathrm{BW}$ & A & $\begin{array}{l}\text { Mass, density, volume and growth of } \\
\text { single cells. Flow-through operation. }\end{array}$ \\
\hline $\begin{array}{l}\text { Craighea } \\
\mathrm{d} 2010 \\
(43)\end{array}$ & CC-beam & $\begin{array}{l}\text { Silicon } \\
\text { Nitride }\end{array}$ & $\mathrm{A} / \mathrm{C}$ & 1 to $5 \mathrm{fl}$ & 7 to 14 & $\begin{array}{l}\text { Optical } \\
\text { (thermal) }\end{array}$ & Optical & $\sim 25 \mathrm{MHz}$ & $\begin{array}{l}\sim 4000 \\
\text { (empty) } \\
\sim 800 \text { (fluid- } \\
\text { filled) }\end{array}$ & $\begin{array}{c}4 \mathrm{ppm} / \mathrm{fg} \\
\sim 16 \mathrm{ppm} /\left(\mathrm{kg} \mathrm{m}^{-3}\right)\end{array}$ & $2 \mathrm{fg}$ in $250 \mathrm{mHz}$ BW & None. (NanoPorts) & Fluid density. \\
\hline $\begin{array}{l}\text { Manalis } \\
2010(71)\end{array}$ & cantilever & Silicon & D & $140 \mathrm{fl}$ & $\sim 3.5$ & Electrostatic & Optical & $\sim 630 \mathrm{kHz}$ & $\sim 8000$ & $\sim 1.6 \mathrm{ppm} / \mathrm{fg}$ & 27 ag in $1 \mathrm{kHz}$ BW & A & $\begin{array}{l}\text { Single mass detection of } \\
\text { nanoparticles via flow-through } \\
\text { operation and inertial trapping. }\end{array}$ \\
\hline $\begin{array}{l}\text { Piazza } \\
2010(67)\end{array}$ & CC-beam & $\begin{array}{l}\text { Aluminum } \\
\text { Nitride }\end{array}$ & B & $1.34 \mathrm{pl}$ & $\sim 6$ & PZE & PZE & $\begin{array}{l}450 \mathrm{MHz} \\
\begin{array}{c}\sim \text { in plane- contour } \\
\text { mode) }\end{array}\end{array}$ & 170 (in air) & N.A. & N.A. & None. & $\begin{array}{l}\text { High frequency piezoelectric } \\
\text { resonator for liquid analysis. }\end{array}$ \\
\hline
\end{tabular}




\begin{tabular}{|c|c|c|c|c|c|c|c|c|c|c|c|c|c|}
\hline $\begin{array}{l}\text { Manalis } \\
2011(61)\end{array}$ & cantilever & Silicon & $\mathrm{D}$ & $\begin{array}{c}26.5 \mathrm{pl} \\
\text { and } \\
51.3 \mathrm{pl}\end{array}$ & 1.7 & $\begin{array}{l}\text { Commercial } \\
\text { Piezoactuator }\end{array}$ & $\begin{array}{l}\text { Piezoresistiv } \\
\text { e }\end{array}$ & $\begin{array}{c}346.6 \mathrm{kHz} \\
\text { and } \\
92.1 \mathrm{kHz}\end{array}$ & $\begin{array}{c}3700 \\
\text { and } \\
10850\end{array}$ & $\begin{array}{l}\sim 15 \mathrm{ppm} / \mathrm{pg} \\
\text { and } \\
\sim 8 \mathrm{ppm} / \mathrm{pg}\end{array}$ & $\begin{array}{l}3.4 \mathrm{fg} \text { in } 1 \mathrm{kHz} \mathrm{BW} \\
\text { and } \\
18.1 \mathrm{fg} \text { in } 1 \mathrm{kHz} \mathrm{BW}\end{array}$ & A & $\begin{array}{l}\text { Mass of single cells via piezoresistive } \\
\text { readout and flow-through operation. }\end{array}$ \\
\hline $\begin{array}{l}\text { Manalis } \\
2011 \text { (94) }\end{array}$ & cantilever & Silicon & $\mathrm{D}$ & N.A. & $\sim 1$ & Electrostatic & Optical & $\sim 389 \mathrm{kHz}$ & $\sim 10000$ & N.A. & $0.001 \mathrm{~g} / \mathrm{ml}$ & A & $\begin{array}{l}\text { Single-cell density via flow-through } \\
\text { detection in different fluids. }\end{array}$ \\
\hline $\begin{array}{c}\text { Boisen } \\
2011(42)\end{array}$ & cantilever & $\begin{array}{l}\text { low stress } \\
\text { Silicon } \\
\text { Nitride }\end{array}$ & B & $6.4 \mathrm{pl}$ & $\sim 0.5$ & $\begin{array}{l}\text { Commercial } \\
\text { Piezoactuator }\end{array}$ & Optical & $\sim 150 \mathrm{kHz}$ & N.A. & $\sim 100 \mathrm{ppm} /\left(\mathrm{kg} \mathrm{m}^{-3}\right)$ & $0.025 \mathrm{~g} / \mathrm{ml}$ & None. & Fluid density. \\
\hline $\begin{array}{l}\text { Caillat } \\
2011(64)\end{array}$ & plate & Silicon & $\mathrm{D}$ & $\sim 250 \mathrm{fl}$ & $\sim 30$ & Electrostatic & Capacitive & $\begin{array}{l}78 \mathrm{MHz} \text { (in plane } \\
\text { - Lamè mode) }\end{array}$ & 3000 (in air) & $15 \mathrm{ppm} / \mathrm{pg}$ & $1.5 \mathrm{fg}$ & A (no vacuum) & $\begin{array}{l}\text { Full-capacitive liquid phase } \\
\text { detection. }\end{array}$ \\
\hline $\begin{array}{c}\text { J. Lee } \\
2012(91)\end{array}$ & cantilever & Silicon & $\mathrm{D}$ & $\sim 50 \mathrm{pl}$ & $\sim 2$ & N.A. & N.A. & $\sim 90 \mathrm{kHz}$ & $\sim 10000$ & $120 \mathrm{ppm} /\left(\mathrm{kg} \mathrm{m}^{-3}\right)$ & $0.035 \mathrm{mPa} \cdot \mathrm{s}$ & A & Fluid viscosity (<10 mPa·s).. \\
\hline $\begin{array}{c}\text { Boisen } \\
2013(79)\end{array}$ & cantilever & $\begin{array}{l}\text { low stress } \\
\text { Silicon } \\
\text { Nitride }\end{array}$ & B & $5 \mathrm{pl}$ & $\sim 0.5$ & $\begin{array}{l}\text { Commercial } \\
\text { Piezoactuator }\end{array}$ & Optical & $\sim 130 \mathrm{kHz}$ & $\sim 15000$ & $\sim 120 \mathrm{ppm} /\left(\mathrm{kg} \mathrm{m}^{-3}\right)$ & $\begin{array}{c}10 \mathrm{ug} / \mathrm{ml} \\
0.025 \mathrm{mPa} \cdot \mathrm{s}\end{array}$ & B & Fluid density and viscosity. \\
\hline $\begin{array}{l}\text { Ono } 2013 \\
\quad(46)\end{array}$ & CC-beam & $\begin{array}{l}\mathrm{SiO}_{2} / \mathrm{ss}- \\
\mathrm{SiN}_{x} / \mathrm{SiO}_{2}\end{array}$ & B & $270 \mathrm{pl}$ & $\sim 0.1$ & $\begin{array}{c}\text { Piezoactuator + } \\
\text { LDV power } \\
\text { heating }\end{array}$ & Optical & $1.25 \mathrm{MHz}$ & 170 (in air) & $\begin{array}{l}140 \mathrm{ppm} / \mathrm{K} \\
8.6 \mathrm{ppm} / \mathrm{\mu W}\end{array}$ & N.A. & None. & $\begin{array}{l}\text { Sensing of local heat generated in } \\
\text { liquids. }\end{array}$ \\
\hline $\begin{array}{l}\text { Manalis } \\
2013(95)\end{array}$ & $\begin{array}{c}\text { dual } \\
\text { cantilever }\end{array}$ & Silicon & $\mathrm{D}$ & $\sim 500 \mathrm{pl}$ & N.A. & Electrostatic & Optical. & $\begin{array}{c}\sim 140 \mathrm{kHz} \\
\text { and } \\
\sim 170 \mathrm{kHz}\end{array}$ & N.A. & $\sim 30 \mathrm{kHz} /(\mathrm{g} / \mathrm{ml})$ & $\sim 0.001 \mathrm{~g} / \mathrm{ml}$ & A & $\begin{array}{l}\text { Single-cell density via dual SMRs } \\
\text { and flow-through detection. }\end{array}$ \\
\hline $\begin{array}{l}\text { Manalis } \\
2013 \\
(105, \\
106)\end{array}$ & $\begin{array}{l}\text { cantilever } \\
\text { with channel } \\
\text { constriction }\end{array}$ & Silicon & $\mathrm{D}$ & $\sim 180 \mathrm{pl}$ & $\sim 1$ & Electrostatic & Optical & $\sim 2 \mathrm{kHz}$ & N.A. & N.A. & $1 \mathrm{pg}$ & A & $\begin{array}{l}\text { Cancer cells deformability an surface } \\
\text { friction in flow-through detection. }\end{array}$ \\
\hline $\begin{array}{l}\text { Staufer } \\
2013 \\
(107)\end{array}$ & cantilever & $\begin{array}{l}\text { Silicon } \\
\text { oxide }\end{array}$ & $\mathrm{D}$ & $\sim 2.5 \mathrm{pl}$ & $\sim 4$ & N.A. & Optical & $\sim 150 \mathrm{kHz}$ & 435 (in air) & $\sim 0.2 \mathrm{ppm} / \mathrm{fg}$ & $\begin{array}{l}\text { Aspiration rate: } 85 \\
\text { al/s }\end{array}$ & None. & $\begin{array}{l}\text { Liquids and nanobeads aspiration via } \\
\text { hollow AFM-cantilever. }\end{array}$ \\
\hline $\begin{array}{c}\text { Burg } \\
2013(65)\end{array}$ & cantilever & Silicon & $\mathrm{D}$ & $2.8 \mathrm{pl}$ & $\sim 1$ & Electrostatic & Optical & $\begin{array}{l}1.17 \mathrm{MHz} \\
\text { (torsional) }\end{array}$ & $\begin{array}{l}6000 \text { (water- } \\
\text { filled) }\end{array}$ & $\begin{array}{l}30 \mathrm{zg} \text { in } 1 \mathrm{kHz} \mathrm{BW} \\
\text { using autcocorrelation } \\
\text { analysis }\end{array}$ & $0.016 \mathrm{ppm} / \mathrm{fg}$ & A & $\begin{array}{l}\text { Mass of single biomolecules and } \\
\text { nanoparticles. Flow-through } \\
\text { operation. }\end{array}$ \\
\hline $\begin{array}{l}\text { Manalis } \\
2014(86)\end{array}$ & cantilever & Silicon & $\mathrm{D}$ & $\begin{array}{l}20 \text { to } 80 \\
\mathrm{fl}\end{array}$ & 5 to 8 & $\begin{array}{l}\text { Commercial } \\
\text { Piezoactuator }\end{array}$ & Optical & $\begin{array}{l}0.589 \mathrm{MHz} \\
\text { to } 2.87 \mathrm{MHz}\end{array}$ & $\sim 15000$ & up to $5.5 \mathrm{ppm} / \mathrm{ag}$ & $0.85 \mathrm{ag}$ in $1 \mathrm{kHz} \mathrm{BW}$ & A & $\begin{array}{l}\text { Weighing nanoparticles, exosomes } \\
\text { and self-assembled DNA structures. } \\
\text { Flow-through operation. }\end{array}$ \\
\hline $\begin{array}{l}\text { Agache } \\
2015(51)\end{array}$ & plate/disk & Silicon & $\mathrm{D}$ & 0.7 to $4 \mathrm{pl}$ & $\begin{array}{l}\sim 50 \text { to } \\
200\end{array}$ & Electrostatic & Capacitive & $\begin{array}{l}20 \text { to } 90 \mathrm{MHz} \text { (in } \\
\text { plane) }\end{array}$ & $\begin{array}{l}\sim 10000 \text { (in } \\
\text { air) }\end{array}$ & N.A. & $\begin{array}{l}4 \mathrm{fg} \text { in } 20 \mathrm{~ms} \\
\text { averaging time }\end{array}$ & B (no vacuum) & $\begin{array}{l}\text { Weighing single particles in liquids } \\
\text { from nm to um scale. Flow-through } \\
\text { operation. }\end{array}$ \\
\hline $\begin{array}{l}\text { Manalis } \\
2015 \\
(108)\end{array}$ & cantilever & Silicon & $\mathrm{D}$ & $560 \mathrm{fl}$ & $\sim 6$ & $\begin{array}{l}\text { Commercial } \\
\text { Piezoactuator }\end{array}$ & Optical & $\begin{array}{l}40.48 \mathrm{kHz} \\
\text { to } \\
1351 \mathrm{kHz}\end{array}$ & $\begin{array}{c}3620 \\
\text { to } \\
7770\end{array}$ & N.A. & $\begin{array}{l}40 \mathrm{ag} \text { (bandwidth } \\
\text { between } 150 \text { and } 500 \\
\mathrm{~Hz} \text { ) }\end{array}$ & A & $\begin{array}{l}\text { High-speed multimode mass sensing } \\
\text { of nanoparticles. Flow-through } \\
\text { operation. }\end{array}$ \\
\hline
\end{tabular}




\begin{tabular}{|c|c|c|c|c|c|c|c|c|c|c|c|c|c|}
\hline $\begin{array}{c}\text { Tamayo } \\
2015 \text { (73) }\end{array}$ & CC beam & Glass & $\mathrm{H}$ & $\sim 20 \mathrm{nl}$ & $\sim 2$ & $\begin{array}{l}\text { Commercial } \\
\text { Piezoactuator }\end{array}$ & Optical & $78 \mathrm{kHz}$ & 130 & $\sim 30 \mathrm{ppm} /\left(\mathrm{kg} \mathrm{m}^{-3}\right)$ & $50 \mathrm{ug} / \mathrm{ml}$ & None. & Real-time monitoring of fluid density \\
\hline $\begin{array}{c}\text { Boisen } \\
2016\end{array}$ & CC-beam & $\begin{array}{l}\text { low stress } \\
\text { Silicon } \\
\text { Nitride }\end{array}$ & B & $\begin{array}{c}\sim 30 \text { to } 50 \\
\mathrm{pl}\end{array}$ & $\sim 1$ & $\begin{array}{l}\text { Commercial } \\
\text { Piezoactuator }\end{array}$ & Optical & N.A. & N.A. & N.A. & N.A. & N.A. & Micron-scale calorimetry. \\
\hline $\begin{array}{l}\text { Manalis } \\
2016- \\
2018(60, \\
96,109)\end{array}$ & $\begin{array}{l}\text { cantilever } \\
\text { array }\end{array}$ & Silicon & $\mathrm{D}$ & $\begin{array}{l}\sim 10 \text { to } \\
180 \mathrm{pl}\end{array}$ & $\sim 1$ to 6 & $\begin{array}{l}\text { Commercial } \\
\text { Piezoactuator }\end{array}$ & $\begin{array}{c}\text { Optical or } \\
\text { piezoresistiv } \\
\mathrm{e}\end{array}$ & $700-1100 \mathrm{kHz}$ & $1500-5000$ & N.A. & $\begin{array}{c}0.2 \mathrm{pg} / \mathrm{h} \text { (cells) } \\
0.02 \mathrm{pg} / \mathrm{h} \text { (bacteria) }\end{array}$ & A. & $\begin{array}{l}\text { High-throughput platform for cell } \\
\text { growth analysis. Cancer cells drug } \\
\text { responsivity. Linked gene expression. } \\
\text { Flow-through operation. }\end{array}$ \\
\hline $\begin{array}{l}\text { Zambelli } \\
2016(49)\end{array}$ & cantilever & SU-8 & B & $\begin{array}{l}\text { from } 10 \\
\text { to } 75 \mathrm{pl}\end{array}$ & $\sim$ & $\begin{array}{l}\text { N.A. (static } \\
\text { deflection) }\end{array}$ & Optical & N.A & N.A. & N.A. & $<\mathrm{nN}$ & None. & $\begin{array}{l}\text { Single cells force spectroscopy of } \\
\text { yeast cells via AFM. }\end{array}$ \\
\hline $\begin{array}{l}\text { Thundat } \\
2016(44)\end{array}$ & cantilever & $\begin{array}{l}\text { low stress } \\
\text { Silicon } \\
\text { Nitride/gol } \\
\text { d }\end{array}$ & B & $\begin{array}{c}48-115 \\
\mathrm{pl}\end{array}$ & $<1$ & $\begin{array}{l}\text { N.A. (static } \\
\text { deflection) }\end{array}$ & Optical & N.A & N.A & $\begin{array}{l}\text { up to } 74 \mathrm{~nm} / \mathrm{mW} \\
\text { up to } 250 \mathrm{~nm} / \mathrm{K}\end{array}$ & $4 \mathrm{mK}, 60 \mu \mathrm{W}, 240 \mathrm{~nJ}$ & None. & $\begin{array}{l}\text { Photothermal cantilever deflection } \\
\text { spectroscopy for biosensing. }\end{array}$ \\
\hline $\begin{array}{c}\text { Barniol } \\
2016(66)\end{array}$ & CC-beam & Metal & A & $6 \mathrm{fl}$ & $\sim 7$ & Electrostatic & Capacitive & $25.4 \mathrm{MHz}$ & 250 (in air) & $25 \mathrm{ag} / \mathrm{Hz}$ & N.A. & None. & $\begin{array}{l}\text { Fabrication of SNR bridges } \\
\text { integrated with CMOS circuitry. } \\
\text { Fully electrical transduction. }\end{array}$ \\
\hline $\begin{array}{l}\text { Lee } 2016 \\
\quad(57)\end{array}$ & $\begin{array}{l}\text { CC-beams } \\
\text { and } \\
\text { cantilevers }\end{array}$ & $\begin{array}{l}\text { Silicon } \\
\text { dioxide }\end{array}$ & G & $\sim$ few fl & $<1$ & $\begin{array}{l}\text { Commercial } \\
\text { Piezoactuator }\end{array}$ & Optical & 0.6 to $7 \mathrm{MHz}$ & $\begin{array}{c}2500 \text { to } \\
14000\end{array}$ & $\begin{array}{l}\text { up to } 1 \mathrm{mHz} /\left(\mathrm{kg} \mathrm{m}^{-3}\right) \\
\text { and } 2.044 \times 10^{19} \mathrm{~Hz} / \mathrm{kg}\end{array}$ & $\begin{array}{l}\text { down to } 0.19 \mathrm{ag} \text { and } \\
0.125 \mathrm{mg} / \mathrm{ml}\end{array}$ & A & $\begin{array}{l}\text { Fluid density. Single mass detection } \\
\text { of microparticles in flow-through } \\
\text { operation. }\end{array}$ \\
\hline $\begin{array}{l}\text { J. Lee, } \\
2016(58)\end{array}$ & CC-beam & glass & $\begin{array}{l}\text { Pulling glass } \\
\text { fibers }\end{array}$ & $4.6 \mathrm{nl}$ & $\sim 0.4$ & $\begin{array}{l}\text { Commercial } \\
\text { Piezoactuator }\end{array}$ & $\begin{array}{c}\text { Quartz } \\
\text { tuning fork }\end{array}$ & $24.5 \mathrm{kHz}$ & 250 (in air) & $\sim 0.13 \mathrm{ppm} /\left(\mathrm{kg} \mathrm{m}^{-3}\right)$ & $\begin{array}{c}31 \mathrm{~nm} \text { (mineral oil } \\
\text { droplet radius) }\end{array}$ & None. & Density and mass sensor. \\
\hline $\begin{array}{l}\text { Thundat, } \\
2017 \\
(110)\end{array}$ & cantilever & $\begin{array}{l}\text { Silicon } \\
\text { dioxide }\end{array}$ & G & $\sim 0.5 \mathrm{pl}$ & $\sim 0.6$ & $\begin{array}{l}\text { Commercial } \\
\text { Piezoactuator }\end{array}$ & Optical & $1.8 \mathrm{MHz}$ & 2500 & $\begin{array}{l}132 \mathrm{ppm} /\left(\mathrm{kg} \mathrm{m}^{-3}\right) \\
\sim 2.4 \mathrm{ppm} / \mu \mathrm{M}(\mathrm{BSA} \\
\text { in DI water) }\end{array}$ & N.A. & A & $\begin{array}{l}\text { Portable platform including capillary } \\
\text { gel electrophoresis-coupled to SMRs } \\
\text { for mass spectroscopy. }\end{array}$ \\
\hline $\begin{array}{l}\text { Villanuev } \\
\text { a 2018 } \\
(45)\end{array}$ & $\begin{array}{l}\text { cantilever } \\
\text { array }\end{array}$ & $\begin{array}{l}\text { low stress } \\
\text { Silicon } \\
\text { Nitride }\end{array}$ & $\mathrm{C}$ & $25 \mathrm{pl}$ & $\sim 1$ & PZE & PZE/optical & $\sim 200 \mathrm{kHz}$ & $\sim 500$ (in air) & $5.6 \mathrm{ppm} / \mathrm{pg}$ & N.A. & None. & Fluid density. \\
\hline $\begin{array}{l}\text { Boisen } \\
2018(54)\end{array}$ & CC-beam & $\begin{array}{l}\text { low stress } \\
\text { Silicon } \\
\text { Nitride }\end{array}$ & $\mathrm{E}$ & $\sim 90 \mathrm{pl}$ & $<1$ & $\begin{array}{l}\text { Commercial } \\
\text { Piezoactuator }\end{array}$ & Optical & N.A. & $\sim 4000$ & N.A. & $2.75 \mathrm{pg}$ in $1 \mathrm{kHz} \mathrm{BW}$ & N.A. & $\begin{array}{l}\text { Multi parameter analysis of liquid } \\
\text { samples and single cells. IR } \\
\text { absorption spectrometry. }\end{array}$ \\
\hline $\begin{array}{l}\text { Ricciardi } \\
2019(55)\end{array}$ & CC-beam & Glass & $\mathrm{F}$ & $157 \mathrm{pl}$ & $\sim 7$ & $\begin{array}{l}\text { Commercial } \\
\text { Piezoactuator }\end{array}$ & Optical & $364.85 \mathrm{kHz}$ & $\sim 2700$ & $\begin{array}{c}0.234 \mathrm{ppm} / \mathrm{pg} \\
24 \mathrm{ppm} /\left(\mathrm{kg} \mathrm{m}^{-3}\right)\end{array}$ & $\begin{array}{c}0.11 \mathrm{pg} \\
1.04 \mathrm{ug} / \mathrm{ml}\end{array}$ & N.A. & $\begin{array}{c}\text { Fluid density and cell mass sensing } \\
\text { (multiple cells inside SMR). Flow- } \\
\text { through operation. }\end{array}$ \\
\hline $\begin{array}{c}\text { Manalis } \\
2019(88)\end{array}$ & cantilever & Silicon & $\mathrm{D}$ & $\sim 200 \mathrm{pl}$ & $\sim 0.6$ & $\begin{array}{l}\text { Commercial } \\
\text { Piezoactuator }\end{array}$ & $\begin{array}{c}\text { Piezoresistiv } \\
\text { e/Optical }\end{array}$ & $\underset{\text { mode })}{\sim 1 \mathrm{MHz}\left(2^{\text {nd }}\right.}$ & N.A. & N.A. & $\begin{array}{l}\text { temporal resolution } \\
<1 \text { min }\end{array}$ & A & $\begin{array}{l}\text { Single cells stiffness via SMRs and } \\
\text { acoustic scattering. Flow-through } \\
\text { operation. }\end{array}$ \\
\hline \multicolumn{14}{|c|}{$\begin{array}{l}\text { * Fabrication type refers to the classification seen in Table 2. Per each paper considered, the closest fabrication process in Table } 2 \text { is assigned. } \\
\text { ** Resonance frequency refers to the } 1^{\text {st }} \text { flexural vibrational mode, unless differently specified. } \\
\text { *** Quality factor refers to resonators operated in vacuum, unless differently specified. }\end{array}$} \\
\hline
\end{tabular}




\section{References}

1. Plodinec M, et al. (2013) The Nanomechanical Signature of Breast Cancer. Biophys J 104(2, Supplement 1):321a.

2. Nematbakhsh Y \& Lim CT (2015) Cell biomechanics and its applications in human disease diagnosis. Acta Mech Sin 31(2):268-273.

3. Brandão MM, et al. (2003) Optical tweezers for measuring red blood cell elasticity: application to the study of drug response in sickle cell disease. European Journal of Haematology 70(4):207-211.

4. Cross SE, et al. (2008) AFM-based analysis of human metastatic cancer cells. Nanotechnology 19(38):384003.

5. Calzado-Martín A, Encinar M, Tamayo J, Calleja M, \& San Paulo A (2016) Effect of Actin Organization on the Stiffness of Living Breast Cancer Cells Revealed by Peak-Force Modulation Atomic Force Microscopy. ACS Nano 10(3):3365-3374.

6. Tomaiuolo $\mathrm{G}$ (2014) Biomechanical properties of red blood cells in health and disease towards microfluidics. Biomicrofluidics 8(5).

7. Guck J \& Chilvers ER (2013) Mechanics Meets Medicine. Sci Transl Med 5(212):212fs241$212 \mathrm{fs} 241$.

8. Wu P-H, et al. (2018) A comparison of methods to assess cell mechanical properties. Nat Methods 15(7):491-498.

9. Arlett JL, Myers EB, \& Roukes ML (2011) Comparative advantages of mechanical biosensors. Nat Nano 6(4):203-215.

10. Boisen A, Dohn S, Keller SS, Schmid S, \& Tenje M (2011) Cantilever-like micromechanical sensors. Rep. Prog. Phys. 74(3):036101.

11. Tamayo J, Kosaka PM, Ruz JJ, Paulo ÁS, \& Calleja M (2013) Biosensors based on nanomechanical systems. Chem. Soc. Rev. 42(3):1287-1311.

12. Gupta A, Akin D, \& Bashir R (2004) Single virus particle mass detection using microresonators with nanoscale thickness. Applied Physics Letters 84(11):1976-1978.

13. Corbin EA, Kong F, Lim CT, King WP, \& Bashir R (2015) Biophysical properties of human breast cancer cells measured using silicon MEMS resonators and atomic force microscopy. Lab Chip 15(3):839-847.

14. Hanay MS, et al. (2012) Single-protein nanomechanical mass spectrometry in real time. Nat Nano 7(9):602-608.

15. Dominguez-Medina S, et al. (2018) Neutral mass spectrometry of virus capsids above 100 megadaltons with nanomechanical resonators. Science 362(6417):918-922.

16. Villanueva G, Plaza JA, Montserrat J, Perez-Murano F, \& Bausells J (2008) Crystalline silicon cantilevers for piezoresistive detection of biomolecular forces. Microelectronic Engineering 85(5):1120-1123.

17. Sorba F \& Martin-Olmos C (2018) High resolution polymer coated strain sensors for in-liquid operation. Microelectronic Engineering 191:38-41.

18. Fritz J, et al. (2000) Translating Biomolecular Recognition into Nanomechanics. Science 288(5464):316-318.

19. Ekinci KL \& Roukes ML (2005) Nanoelectromechanical systems. Review of Scientific Instruments 76(6):061101.

20. Sansa M, et al. (2016) Frequency fluctuations in silicon nanoresonators. Nat Nano 11(6):552-558.

21. Chaste J, et al. (2012) A nanomechanical mass sensor with yoctogram resolution. Nat Nano 7(5):301.

22. Sader JE (1998) Frequency response of cantilever beams immersed in viscous fluids with applications to the atomic force microscope. Journal of Applied Physics 84(1):64-76.

23. Waggoner PS, Varshney M, \& Craighead HG (2009) Detection of prostate specific antigen with nanomechanical resonators. 9(21):3095-3099.

24. Gfeller KY, Nugaeva N, \& Hegner M (2005) Rapid Biosensor for Detection of Antibiotic-Selective Growth of Escherichia coli. Appl. Environ. Microbiol. 71(5):2626-2631.

25. Ghatkesar MK, et al. (2008) Resonating modes of vibrating microcantilevers in liquid. Applied Physics Letters 92(4):043106.

26. Durmuş NG, et al. (2015) Acoustic-Based Biosensors. Encyclopedia of Microfluidics and Nanofluidics, ed Li D (Springer New York), pp 2840.

27. Vashist SK \& Vashist P (2011) Recent Advances in Quartz Crystal Microbalance-Based Sensors. Journal of Sensors 2011:e571405.

28. Länge K, Rapp BE, \& Rapp M (2008) Surface acoustic wave biosensors: a review. Anal Bioanal Chem 391(5):1509-1519.

29. Senveli SU, et al. (2015) A surface acoustic wave biosensor for interrogation of single tumour cells in microcavities. 16(1):163-171.

30. Kim N, Kim D-K, \& Cho Y-J (2009) Development of indirect-competitive quartz crystal microbalance immunosensor for C-reactive protein. Sensors and Actuators B: Chemical 143(1):444-448.

31. Rodahl M, Höök F, Krozer A, Brzezinski P, \& Kasemo B (1995) Quartz crystal microbalance setup for frequency and Q-factor measurements in gaseous and liquid environments. Review of Scientific Instruments 66(7):3924-3930.

32. Rocha-Gaso M-I, March-Iborra C, Montoya-Baides Á, \& Arnau-Vives A (2009) Surface Generated Acoustic Wave Biosensors for the Detection of Pathogens: A Review. Sensors (Basel) 9(7):57405769.

33. Fang L, Lifeng Q, Huiyan W, \& Wang Q (2014) Love mode surface acoustic wave sensors for cellular 
toxicity sensing. 2014 IEEE International Ultrasonics Symposium, pp 2548-2551.

34. Oesterschulze E, et al. (2012) Tailoring the interface of hybrid microresonators in viscid fluids enhances their quality factor by two orders of magnitude. $L a b$ Chip 12(7):1316-1319.

35. Ziegler D \& Ashby PD (2012) Encased Cantilevers for Ultra-Low-Noise Force Spectroscopy of Proteins and Ligand Receptor Complexes. Biophys J 102(3, Supplement 1):579a.

36. Melli M, Scoles G, \& Lazzarino M (2011) Fast Detection of Biomolecules in Diffusion-Limited Regime Using Micromechanical Pillars. ACS Nano 5(10):7928-7935.

37. Burg TP \& Manalis SR (2003) Suspended microchannel resonators for biomolecular detection. Applied Physics Letters 83(13):2698-2700.

38. Anonymous (2016) Oscillating U-tube. in Wikipedia.

39. Anonymous (Stabinger Messtechnik.

40. Burg TP, et al. (2007) Weighing of biomolecules, single cells and single nanoparticles in fluid. Nature 446(7139):1066-1069.

41. Williams KR, Gupta K, \& Wasilik M (2003) Etch rates for micromachining processing-Part II. Journal of Microelectromechanical Systems 12(6):761-778.

42. Khan MF, Schmid S, Davis ZJ, Dohn S, \& Boisen A (2011) Fabrication of resonant micro cantilevers with integrated transparent fluidic channel. Microelectronic Engineering 88(8):2300-2303.

43. Barton RA, et al. (2010) Fabrication of a Nanomechanical Mass Sensor Containing a Nanofluidic Channel. Nano Lett. 10(6):2058-2063.

44. Miriyala N, Khan MF, \& Thundat T (2016) Thermomechanical behavior of a bimaterial microchannel cantilever subjected to periodic IR radiation. Sensors and Actuators B: Chemical 235:273-279.

45. De Pastina A, Maillard D, \& Villanueva LG (2018) Fabrication of suspended microchannel resonators with integrated piezoelectric transduction. Microelectronic Engineering 192:83-87.

46. Toda M, Otake T, Miyashita H, Kawai Y, \& Ono T (2013) Suspended bimaterial microchannel resonators for thermal sensing of local heat generation in liquid. Microsyst Technol 19(7):10491054.

47. Marquez S, et al. (2017) Asymmetrically coupled resonators for mass sensing. Applied Physics Letters 111(11):113101.

48. De Pastina A, Aupée AND, Larsen T, \& Villanueva G (2016) Parylene-Based Hollow Nanomechanical Resonators For Bioapplications. 42nd Micro and Nano Engineering Conference.

49. Martinez V, et al. (2016) SU-8 hollow cantilevers for AFM cell adhesion studies. J. Micromech. Microeng. 26(5):055006.

50. Corman T, Enoksson P, Norén K, \& Stemme G (2000) A low-pressure encapsulated resonant fluid density sensor with feedback control electronics. Meas. Sci. Technol. 11(3):205.

51. Hadji C, et al. (2015) Hollow MEMS mass sensors for real-time particles weighing and sizing from a few $10 \mathrm{~nm}$ to the um scale. 2015 28th IEEE International Conference on Micro Electro Mechanical Systems (MEMS), pp 180-183.

52. Groenesteijn J, Boer MJd, Lötters JC, \& Wiegerink RJ (2017) A versatile technology platform for microfluidic handling systems, part I: fabrication and functionalization. Microfluid Nanofluid 21(7):127.

53. Dijkstra M, et al. (2007) A versatile surface channel concept for microfluidic applications. J. Micromech. Microeng. 17(10):1971.

54. Larsen PE, Viehrig M, \& Boisen A (2018) A resonant hollow MEMS device for multi-dimension analysis. 44th International conference on Micro and Nano Engineering:3.

55. Calmo R, et al. (2019) Monolithic glass suspended microchannel resonators for enhanced mass sensing of liquids. Sensors and Actuators B: Chemical 283:298-303.

56. Accoto C, et al. (2015) Two-Photon Polymerization Lithography and Laser Doppler Vibrometry of a SU8-Based Suspended Microchannel Resonator. Journal of Microelectromechanical Systems 24(4):1038-1042.

57. Kim J, et al. (2016) Hollow Microtube Resonators via Silicon Self-Assembly toward Subattogram Mass Sensing Applications. Nano Lett 16(3):1537-1545.

58. Lee D, et al. (2016) Pulled microcapillary tube resonators with electrical readout for mass sensing applications. Scientific Reports 6:33799.

59. Larsen T, et al. (2017) Position and mode dependent optical detection back-action in cantilever beam resonators. J. Micromech. Microeng. 27(3):035006.

60. Cermak N, et al. (2016) High-throughput measurement of single-cell growth rates using serial microfluidic mass sensor arrays. Nat Biotechnol 34(10):1052-1059.

61. Lee J, et al. (2011) Suspended microchannel resonators with piezoresistive sensors. Lab Chip 11(4):645-651.

62. Weng Y, et al. (2011) Mass sensors with mechanical traps for weighing single cells in different fluids. $L a b$ Chip 11(24):4174-4180.

63. Enoksson P, Stemme G, \& Stemme E (1995) Vibration mode investigation of a resonant silicon tube structure for use as a fluid density sensor. IEEE Micro Electro Mechanical Systems, 1995, MEMS '95, Proceedings, pp 133-.

64. Agache V, Blanco-Gomez G, Baleras F, \& Caillat P (2011) An embedded microchannel in a MEMS plate resonator for ultrasensitive mass sensing in liquid. Lab Chip 11(15):2598-2603.

65. Modena MM, Wang Y, Riedel D, \& Burg TP (2013) Resolution enhancement of suspended microchannel 
resonators for weighing of biomolecular complexes in solution. 14(2):342-350.

66. Vidal-Álvarez G, Marigó E, Torres F, \& Barniol N (2016) Fabrication and Measurement of a Suspended Nanochannel Microbridge Resonator Monolithically Integrated with CMOS Readout Circuitry. Micromachines 7(3):40.

67. Zuniga C, Rinaldi M, \& Piazza G (2010) High frequency Piezoelectric Resonant Nanochannel for bio-sensing applications in liquid environment. 2010 IEEE Sensors, pp 52-55.

68. Doll JC \& Pruitt BL (2010) Design of piezoresistive versus piezoelectric contact mode scanning probes. J. Micromech. Microeng. 20(9):095023.

69. Schmid S, Villanueva LG, \& Roukes ML (2016) Fundamentals of Nanomechanical Resonators (Springer International Publishing).

70. Ivaldi P, et al. (2011) $50 \mathrm{~nm}$ thick AlN film-based piezoelectric cantilevers for gravimetric detection. $J$. Micromech. Microeng. 21(8):085023.

71. Lee J, Shen W, Payer K, Burg TP, \& Manalis SR (2010) Toward Attogram Mass Measurements in Solution with Suspended Nanochannel Resonators. Nano Lett. 10(7):2537-2542.

72. Groenesteijn J, Boer MJd, Lötters JC, \& Wiegerink RJ (2017) A versatile technology platform for microfluidic handling systems, part II: channel design and technology. Microfluid Nanofluid 21(7):126.

73. Malvar O, et al. (2015) Highly Sensitive Measurement of Liquid Density in Air Using Suspended Microcapillary Resonators. Sensors (Basel) 15(4):7650-7657.

74. Gaitas A \& Hower RW (2014) SU-8 microcantilever with an aperture, fluidic channel, and sensing mechanisms for biological and other applications. $J$ Micro Nanolithogr MEMS MOEMS 13(3).

75. Temiz Y, Lovchik RD, Kaigala GV, \& Delamarche E (2015) Lab-on-a-chip devices: How to close and plug the lab? Microelectronic Engineering 132:156175.

76. Abgrall P \& Gué AM (2007) Lab-on-chip technologies: making a microfluidic network and coupling it into a complete microsystem-a review. J. Micromech. Microeng. 17(5):R15.

77. Esashi M (2008) Wafer level packaging of MEMS J. Micromech. Microeng. 18(7):073001.

78. Burg TP, et al. (2006) Vacuum-Packaged Suspended Microchannel Resonant Mass Sensor for Biomolecular Detection. Journal of Microelectromechanical Systems 15(6):1466-1476.

79. Khan MF, et al. (2013) Online measurement of mass density and viscosity of $\mathrm{pL}$ fluid samples with suspended microchannel resonator. Sensors and Actuators B: Chemical 185:456-461.

80. Burg TP \& Manalis SR (2005) Microfluidic packaging of suspended microchannel resonators for biomolecular detection. $20053 r d$ IEEE/EMBS
Special Topic Conference on Microtechnology in Medicine and Biology, pp 264-267.

81. Maillard D, De Pastina A, Larsen T, \& Villanueva LG (2019) Modular interface and experimental setup for in-vacuum operation of microfluidic devices. Review of Scientific Instruments 90(4):045006.

82. Plaza JA, et al. (2006) T-shaped microcantilever sensor with reduced deflection offset. Applied Physics Letters 89(9):094109.

83. Gavartin E, Verlot P, \& Kippenberg TJ (2013) Stabilization of a linear nanomechanical oscillator to its thermodynamic limit. Nature Communications 4:2860

84. Godin M, et al. (2010) Using buoyant mass to measure the growth of single cells. Nat Methods 7(5):387-390.

85. Lee J, Bryan AK, \& Manalis SR (2011) High precision particle mass sensing using microchannel resonators in the second vibration mode. Review of Scientific Instruments 82(2):023704.

86. Olcum S, et al. (2014) Weighing nanoparticles in solution at the attogram scale. PNAS 111(4):13101315 .

87. Malvar O, et al. (2016) Mass and stiffness spectrometry of nanoparticles and whole intact bacteria by multimode nanomechanical resonators. Nature Communications 7(1):1-8.

88. Kang JH, et al. (2019) Noninvasive monitoring of single-cell mechanics by acoustic scattering. Nat Methods 16(3):263-269.

89. Anonymous (1967) Oscillating U-tube. in Wikipedia. 90. Leopold $\mathrm{H}$ \& Stabinger $\mathrm{H}$ (1989) United S US4838084A (1989-06-13).

91. Lee I, Park K, \& Lee J (2012) Note: Precision viscosity measurement using suspended microchannel resonators. Review of Scientific Instruments 83(11):116106.

92. Sader JE, Burg TP, \& Manalis SR (2010) Energy dissipation in microfluidic beam resonators. Journal of Fluid Mechanics 650:215-250.

93. von Muhlen MG, Brault ND, Knudsen SM, Jiang S, \& Manalis SR (2010) Label-Free Biomarker Sensing in Undiluted Serum with Suspended Microchannel Resonators. Anal. Chem. 82(5):1905-1910.

94. Grover WH, et al. (2011) Measuring single-cell density. PNAS 108(27):10992-10996.

95. Bryan AK, et al. (2013) Measuring single cell mass, volume, and density with dual suspended microchannel resonators. Lab Chip 14(3):569-576.

96. Stevens MM, et al. (2016) Drug sensitivity of single cancer cells is predicted by changes in mass accumulation rate. Nat Biotech 34(11):1161-1167.

97. Cetin AE, et al. (2017) Determining therapeutic susceptibility in multiple myeloma by single-cell mass accumulation. Nature Communications 8(1):1613. 
98. Kimmerling RJ, et al. (2018) Linking single-cell measurements of mass, growth rate, and gene expression. bioRxiv:331686.

99. Dextras P, Burg TP, \& Manalis SR (2009) Integrated Measurement of the Mass and Surface Charge of Discrete Microparticles Using a Suspended Microchannel Resonator. Anal. Chem. 81(11):45174523.

100. Calleja M, Kosaka PM, Paulo ÁS, \& Tamayo J (2012) Challenges for nanomechanical sensors in biological detection. Nanoscale 4(16):4925-4938.

101. Arlett JL \& Roukes ML (2010) Ultimate and practical limits of fluid-based mass detection with suspended microchannel resonators. Journal of Applied Physics 108(8):084701.

102. Dijkstra M, et al. (2008) Miniaturized thermal flow sensor with planar-integrated sensor structures on semicircular surface channels. Sensors and Actuators A: Physical 143(1):1-6.

103. Son S, Grover WH, Burg TP, \& Manalis SR (2008) Suspended Microchannel Resonators for Ultralow Volume Universal Detection. Anal. Chem. 80(12):4757-4760.

104. Bryan AK, Goranov A, Amon A, \& Manalis SR (2010) Measurement of mass, density, and volume during the cell cycle of yeast. PNAS 107(3):9991004.

105. Byun S, et al. (2013) Characterizing deformability and surface friction of cancer cells. PNAS 110(19):7580-7585.

106. Shaw Bagnall J, et al. (2015) Deformability of Tumor Cells versus Blood Cells. Scientific Reports 5:18542.

107. Garza HHP, Ghatkesar MK, \& Staufer U (2013) Aspiration through hollow cantilever-based nanopipette by means of evaporation. IET Micro Nano Letters 8(11):758-761.

108. Olcum S, Cermak N, Wasserman SC, \& Manalis SR (2015) High-speed multiple-mode mass-sensing resolves dynamic nanoscale mass distributions. Nature Communications 6:7070.

109. Kimmerling RJ, et al. (2018) Linking single-cell measurements of mass, growth rate, and gene expression. Genome Biology 19(1):207.

110. Chaudhari S, et al. (2017) Electrophoresis assisted time-of-flow mass spectrometry using hollow nanomechanical resonators. Scientific Reports $7(1): 3535$. 